\title{
Intraday volatility smile: Effects of fragmentation and high frequency trading on price efficiency
}

\author{
Stephanie Ligot ${ }^{\mathrm{a}, *}$, Roland Gillet ${ }^{\mathrm{a}, \mathrm{b}}$, Iryna Veryzhenko ${ }^{\mathrm{a}, \mathrm{c}}$ \\ a Sorbonne Management School (PRISM Sorbonne and Labex ReFi), University Paris 1 Panthéon - Sorbonne, Rue de la Sorbonne 17, F-75231 Paris \\ Cedex 05, France \\ ${ }^{\mathrm{b}}$ Solvay Brussels School of Economics and Management (CEBRIG), Free University of Brussels, Avenue F.D. Roosevelt 42, B-1050 Brussels, Belgium \\ ${ }^{c}$ CNAM Paris, 292 rue St-Martin, 75003 Paris, France
}

\section{A R T I C L E I N F O}

\section{JEL classification:}

G12

G14

G18

\section{Keywords:}

Market efficiency

Intraday data

High-Frequency trading

\begin{abstract}
A B S T R A C T
In 2007, the European Markets in Financial Instruments Directive ended the national concentration rule. As a result, market fragmentation has accelerated across multiple trading venues. Spatial fragmentation might create opportunities and incentives for High Frequency arbitrageurs to fill the void left by the lack of Reg NMS type order routing requirements in Europe, without neglecting market integrity. This paper examines intra-day volatility and price efficiency through the metric of the normalized volatility ratio for the years 2006, 2012 and 2013 for Euronext Paris, BATS and Chi-X Europe. Our findings show that price determination remains inefficient at market opening due to the complexity of price discovery activity following a period of non-trading and heavy information releases. However, we demonstrate that an active participation of highfrequency traders significantly improves market efficiency at opening session.
\end{abstract}

\section{Introduction}

Since 2007, the European Markets in Financial Instruments Directive (MiFID) has attempted to further the integration, competitiveness, and efficiency of European financial markets through the improvement of the quality of order execution by promoting a reduction of transaction costs. Consequently, the MiFID abolished the possibility for member states to require all trading in financial instruments to take place on traditional national regulated markets (RMs) by suppressing the rule of national order concentration, which has enabled European-wide competition between RMs, multilateral trading facilities (MTFs), dark pools and the systematic internalizers introduced by the directive.

In Europe, the development of MTFs is accelerating the movement of trade away from established exchanges. Changing a stocks microstructure may induce price changes due to both enhanced liquidity and greater informational efficiency in trading prices, and particular trading systems may provide more or better information.

O'Hara and Ye (2011) highlighted that the lack of a consolidated tape collecting price feeds from all execution venues at the European level greatly inhibits the ability to establish market-wide trade-through protection. Without such protection, it is hard to see how a single virtual market can emerge. ${ }^{1}$ However, the spatial fragmentation might create opportunities and incentives for high

\footnotetext{
* Corresponding author.

E-mail address: stephanie.ligot@univ-paris1.fr (S. Ligot).

${ }^{1}$ Putting in place trade-through protection and unified trade and price reporting protocols could set the stage for substantial improvements in market quality. Conversely, in markets where such protections cannot be implemented, fragmentation is likely to be more detrimental than not.
} 
frequency arbitrageurs to fill the void left by the lack of Reg NMS type order routing requirements in Europe, without neglecting the importance of Market Integrity ${ }^{2}$ under MiFID II and Market Abuse regulation (MAR). They intend to regulate the risks arising from HFT and provide measures regarding market manipulation that are capable of being adapted to new forms of trading.

Few papers have studied the impacts of increased fragmentation on market quality since the implementation of the MiFID. Our paper complements the literature by comparing the effectiveness of regulatory solutions like Reg NMS versus market-based solutions in MiFID directive. Our analysis provides empirical evidence on the relationship between fragmentation and intra-day market efficiency for the CAC40 stock Index (before and after the implementation of MiFID) in normal market conditions. Furthermore, we analyze whether high-frequency trading firms contribute to providing price efficiency at market opening. In this way, this article expands on prior research by Ozenbas et al. (2010) by incorporating the potential contribution of high-frequency trading firms to price efficiency in a fragmented market. Compared to O'Hara and Ye (2011) and Ozenbas et al. (2010), we provide evidence that High-Frequency trading reduces price inefficiency of the first half-hour opening time after the implementation of the MiFID.

We focus on intraday volatility as a manifestation of the efficiency with which prices are set. Inefficient pricing can lead to unduly high execution costs for both types of categories, high-frequency traders as well as long-term investors. To address the fragmentation and market quality issues, we use new database BEDOFIH ${ }^{3}$ which gathers microsecond-grain order flow and trades on AMF - NYSE Euronext Paris, the IODS BATS, and Chi-X. Moreover, in this database all traders are classified into three categories: HFTs, non-highfrequency traders (non-HFTs), and mixed traders (MTs). Our analysis yields a number of results, and our contributions are threefold.

First, we develop monthly indicators of fragmentation for each stock in the post-MiFID environment. Based on data provided by Fidessa, we measure the monthly evolution of market shares for the dark pools, the Lit trading corresponding to the trading on Limit Order Books (LOB), and the off-trading for the CAC40 stocks in the post-MiFID environment. To assess the degree of spatial fragmentation introduced by the MiFID, we also measure the Fidessa Fragmentation Index (FFI) in these individual stocks.

Second, we focus on the short-term return volatility measured by the monthly normalized volatility ratios for the CAC40 stocks on the NYSE Euronext Paris and the main MTFs. We assess volatility for each individual half-hour period in the trading day. This price efficiency metric offers a close look at the evolution of intra-day price volatility, especially regarding how it varies across the trading days for the opening, midday and closing periods and across the different trading venues. We find a significant market inefficiency during opening session and particularly improved market efficiency at market closing after the implementation of the MiFID for the cross-listed CAC40 stocks.

Third, we clarify some reasons of deteriorated efficiency at market opening and closing on the NYSE Euronext Paris. We find that price efficiency, as measured by normalized volatility ratios for the first half-hour, is not harmed by spatial fragmentation.

However, price discovery inefficiency at market opening and closing is strongly impacted by price discovery activity. We also show that active participation of high-frequency traders at market opening have positive effect on price efficiency in the post-MiFID environment.

This article is organized as follows. The next section describes our arguments regarding the links between fragmentation and price efficiency. Section 3 presents our databases, our sample period and our methodology. Section 4 gives our results and the causes of price inefficiency at market opening and closing in the post-MiFID context, where the impacts of the Financial Transaction Tax on HFTs activities are also studied. Our conclusion is given in Section 5 .

\section{Literature review}

O'Hara and Ye (2011) defines market quality as a market's ability to meet its dual goals of liquidity and price discovery. The price discovery process can be defined as the incorporation of new information into asset prices (Hasbrouck, 1995). The intra-day volatility is a manifestation of the efficiency with which prices are set. Inefficient pricing can lead to high execution costs for the market on aggregate. Ozenbas et al. (2002) and Ozenbas et al. (2010) underline that because market openings and closings are stressful periods relative to the midday periods, the intraday volatility pattern has been observed to be U-shaped, which is a manifestation of noise. We define this U-shaped intraday volatility pattern as the "Volatility Smile". In our paper, we show how the High Frequency Traders have an impact on the "Intraday Volatility Smile" at the opening and the closing. How do they contribute to the smile in a context of market fragmentation? This question is quite important to understand the new realities of the high frequency world.

At the intra-day level, the stock prices respond largely to information change and microstructure factors, such as transaction costs, blockages, and the complexities of price discovery. Biais et al. (1999) show that as market opening gets closer, the informational content and efficiency of prices increase, and the learning hypothesis is not rejected (see Boussetta et al., 2017 for a study on the role of pre-opening mechanisms in fragmented markets). We focus on the market quality metrics related to the short-term volatility in a fragmented market to assess the evolution of the intraday market efficiency at market opening in the post-MiFID environment.

\subsection{Does market fragmentation improve market quality?}

A key question is how competition and fragmentation affect market quality in terms of liquidity and price discovery efficiency in the post-MiFID multi-market environment. Theoretical studies provide evidence in favor of both market consolidation and market

\footnotetext{
${ }^{2}$ Austin, Janet, What Exactly Is Market Integrity? An Analysis of One of the Core Objectives of Securities Regulation (July 27, 2016). 2017 8(2) William \& Mary Business Law Review 215, Available at SSRN: https://ssm.com/abstract=2814986 or https://doi.org/10.2139/ssrn.2814986.

${ }^{3}$ BEDOFIH is the Base Européenne de Données Financières à Haute Fréquence.
} 
fragmentation.

For a review of the consolidation versus fragmentation debate, see Gomber et al. (2017). Theoretical works arguing in favor of consolidation are based on the idea that exchanges are often viewed as natural monopolies due to the presence of network externalities and economies of scale (Madhavan, 1995).

Heterogeneity in traders' preferences may imply market fragmentation because no single venue can serve the interests of all investors (Harris, 1993; Biais and Foucault, 2014). The empirical evidence is mixed regarding whether market quality is higher in a fragmented or consolidated equity market. Bennett and Wei (2006) find that overall execution costs fall when the stocks move from trading on the more fragmented Nasdaq market to the more consolidated NYSE. Gajewski and Gresse (2007) find that trading costs in Europe are lower in a centralized order book than when orders are split between an order book and competing dealers. O'Hara and Ye (2011) show that in the U.S., fragmentation is associated with higher short-term volatility but greater market efficiency, as prices are closer to being a random walk.

This result confirms the existence of a virtually consolidated equity market in the U.S. Aitken et al. (2017) find that fragmentation significantly improves market quality, with a reduction of spreads for stocks that are least constrained by the minimum tick size, while constrained stocks experience significant increases in depth in the U.S. Buckle et al. (2018) underline that a fragmented market can generate higher execution speed in conjunction with lower execution costs. In the EU, Foucault and Menkveld (2008) demonstrate that liquidity measured by depth increased when trading expanded, supporting the notion that fragmentation of order flow can enhance the liquidity supply.

Moreover, Gresse (2017) underlines that either dark trading or fragmentation between Lit order books is found to harm liquidity. Our study employs recent data to study the market efficiency among the NYSE Euronext Paris - an RM - and MTFs such as BATS and Chi-X Europe in the fragmented context introduced by MiFID.

\subsection{What are the impacts of high-frequency trading on market quality?}

Another important issue is the effect of high-frequency trading on market quality in fragmented environment. Biais and Foucault (2014) underline that some analysts view this trading practice as beneficial because automation reduces the cost of fragmentation and liquidity provision (see also Aitken et al., 2015; Chaboud et al., 2014). Empirical studies on market efficiency conclude that markets now reflect information more quickly than they did in the past, resulting in prices more accurately reflecting underlying asset values (see, for example, Hasbrouck and Saar (2013), O'Hara and Ye (2011), and Brogaard et al. (2014)). Moreover, Carrion (2013), Hendershott et al. (2011), and Brogaard et al. (2014) show that HFTs facilitate price efficiency and price discovery by trading in the direction of permanent price changes and in the opposite direction of transitory pricing errors both on average and on the highest volatility days through their liquidity demanding orders, whereas HFTs' liquidity supplying orders are adversely selected.

Evidence from Hendershott et al. (2011), Riordan and Storkenmaier (2012) and Hagströmer and Nordén (2013) also suggests that high-frequency trading is associated with decreasing spreads, increasing depth displayed in the limit order book, and decreasing shortterm volatility. Furthermore, Aitken et al. (2015) find that the presence of high-frequency trading has significantly mitigated the frequency and severity of end-of-day price dislocation, and Conrad et al. (2015) show that higher quotation activity in the US is associated with price series that more closely resemble a random walk and a significantly lower cost of trading. Conclusions of Aitken et al. (2015) focusing on closing period are confirmed in our study on market opening period. In addition, we provide evidence on the contribution of high-frequency trading firms to price efficiency at market opening on the Regulated Market (RM).

\section{Data description}

Our paper measures spatial and temporal fragmentation for CAC40 stocks after the implementation of the MiFID. Moreover, we study the evolution of the intra-day volatility pattern and the price efficiency of the trading and the quoting activity on the NYSE Euronext Paris after the implementation of the MiFID and for the quoting activity on MTFs such as BATS and Chi-X Europe.

The causes of price inefficiencies at market opening and closing after the implementation of MiFID will be studied in the multivariate analysis through a regression analysis on the NYSE Euronext Paris. Our analysis focuses on the French equity market. We select only the stocks that were a part of the French CAC40 index at both the beginning and the end of the year. We eliminated any stock that was added to the index during each of the year of our sample.

Our sample comprises a list of 30 individual stocks. For this sample, we assess the level of spatial fragmentation with the Fidessa Fragmentation Index (FFI) and the level of temporal fragmentation through the average number of transactions per month on a stockby-stock basis in the post-MiFID context. The period of study for the post-MiFID period is from 1 May 2012 until 30 April 2013.

The novelty of our study is in the fact that few papers have studied the price efficiency in the post-MiFID context at an intraday level. Moreover, there are few papers studying the role of High-Frequency Traders on such a metric for the European markets. Our rich dataset allows us to provide more details on the behavior of HFTs and their effects on price efficiency at the opening and the closing, which are two sensitive periods.

Afterwards, our analysis uses the BEDOFIH AMF - NYSE Euronext Paris High-Frequency database to measure the normalized volatility ratios for selected stocks after the implementation of the MiFID. This metric is computed on a monthly basis for each firm for 
the first half-hour, the last half-hour and the open-to-close periods. We use two years to check the robustness of our metric. Based on the transaction prices, we study a one-year period before and after the implementation of the MiFID. ${ }^{4}$ As the directive was implemented in 2007, we choose a pre-MiFID period from January 1, 2006 to December 31, 2006 before the financial crisis of 2007-2008. Due to the financial crisis and to be certain of the effective competition between the RM and the MTFs introduced by the MiFID in 2007, we choose a post-MiFID period from May 1, 2012, to April 30, 2013. Few studies use a long period to check the robustness of transaction prices. Moreover, we need to choose a common post-period, where the data are available to compare the metrics between the NYSE Euronext Paris and the MTFs.

Finally, as we are interested in the role of HFTs in the accentuated intra-day stock price volatility at market opening, we choose the most recent post-MiFID period available with flags on the type of traders, including HFTs, allowing a comparison of quoting activity in terms of price efficiency for the three Lit marketplaces. The descriptive statistics for our sample are provided in Table 1. Our dataset relies on the classification of traders achieved by the AMF (Autorité des Marchés Financiers) by comparing the life duration median for their modified or cancelled orders with the overall life duration median for modified or cancelled orders. There are three types of traders: the pure High-Frequency Traders (HFTs), the traders operating both High-Frequency and non-High-Frequency (MIXED HFTs investment banks) and the non-High-Frequency traders (NON-HFTs). Once a trader is classified, it is immutable.

By definition, there cannot be cases where a trader sent an order with the label HFT and another one where he is labelled MIXED. The classification is based on the lifetime of cancelled orders and is determined using two sets of criteria:

a. Through a comparison with other participants: a participant is a pure HFT if the average lifetime of its cancelled orders is less than the average lifetime of all orders in the book and if it has cancelled at least 100,000 orders during the year.

b. With a set threshold: the participant must have cancelled at least 500,000 orders with a lifetime of less than $0.1 \mathrm{~s}$ (i.e. the participant quickly updates the orders in the limit order book) and the top percentile of the lifetime of its cancelled orders must be $<500$ microseconds (i.e. the participant regularly uses fast access to the market). A participant is a high-frequency trader if it meets one of these conditions; an investment bank meeting one of these conditions is described as mixed.

We also compute the normalized volatility ratios based on the spread midpoint from the limit order book of the NYSE Euronext Paris from the BEDOFIH AMF - NYSE Euronext Paris High-Frequency database and from the limit order books of the BATS and Chi-X Europe from the IODs BATS Chi-X intra-day database.

The aim is to compare the normalized volatility ratios for the CAC40 stocks between the RM and the MTFs in December 2012, February 2013 and April 2013, which allows us to compare the results for the quoting activity with those of the trading activity on the NYSE Euronext Paris. These three months correspond to a highly fragmented environment.

\section{Results and discussion}

\subsection{Market fragmentation}

Our analysis focuses on the spatial fragmentation and the temporal fragmentation of markets since the implementation of MiFID. To measure the level of fragmentation within the financial sector, we compute the FFI that allows us to assess the concentration of orders within a given trading venue. The FFI was developed to give a complete picture of how trading of a given stock is broken down across the Lit venues with the orders on-book, the dark pools with the orders that are not visible pre-trade, the systematic internalizers and the bilateral off-book trades with the trades executed over the counter and reported to one of the reporting venues. The market share of each venue is calculated as the percentage of the total consideration traded by that venue over the total consideration traded by all the venues in the supported indices. However, for Europe, the U.S., Canada and Japan, only the order book trades, termed Lit trades, are included in the FFI calculations. The FFI is defined as the inverse of the sum of the squares of the market shares of each individual trading venue. Thus, the FFI ranges from one for a single execution venue to $V_{n}$, the total number of trading venues.

$$
F F I=\frac{1}{\sum_{i=1}^{N}\left(\text { MarketShare }_{i}\right)^{2}}
$$

The rationale behind taking the inverse of this value is that we are measuring a move away from the status quo of a single stock exchange with a monopolistic hold on liquidity (in this case, the FFI is one) to a fragmented marketplace with a number of new trading venues taking the market share (in this case, the FFI is more than one). The major benefit of the FFI is that it gives more weight to venues with the largest market share.

Table 2 reports the monthly parts of the Lit, dark trading and off-book market shares to assess the different types of fragmentation in the post-MiFID environment. Our findings show that off-book trading plays an important role after the implementation of the MiFID (on average $41.78 \%$ for our sample), but dark trading and systematic internalizers remain limited to less than five percent (on average $3.28 \%$ ), even though we observe a slow increase for our sample. The market shares on the limit order books is $54.94 \%$ on average. It remains the largest market share in the post-MiFID environment.

Then, we measure the FFI to assess the monthly spatial fragmentation on the Lit market for each stock of the CAC40 firms for the

\footnotetext{
${ }^{4}$ Ozenbas et al. (2011) also use two years (2000 and 2004) to study the U.S. equity market after the implementation of the Reg NMS.
} 
Table 1

Descriptive statistics - Our sample concerns 30 individual CAC40 stocks on NYSE Euronext Paris. The total number of stocks in circulation is given regarding the beginning of the year and the average price of the first month. The description regards the average monthly stock price, the average monthly market capitalization based on the monthly average price, the average monthly number of transactions and the average monthly number of stocks exchanged per stock. These statistics are computed for the pre-MiFID period of 2006 and the post-MiFID period of May 2012 to May 2013.

\begin{tabular}{lll}
\hline & NYSE Euronext Paris \\
\cline { 2 - 3 } Summary statistics & 2006 & $2012-2013$ \\
\hline Total average market capitalisation (000 000 euros) & 31570,64 & 27691,21 \\
Average stock price (euros) & 64,01 & 43,99 \\
Number of stocks & 30 & 30 \\
Average monthly volume & 608,89 & 376,05 \\
Average monthly number of shares traded per stock & 93162,14 & 167780,7 \\
\hline
\end{tabular}

Table 2

Average market shares for the CAC40 stocks based on the Fidessa data in the post-MiFID environment (May 2012-April 2013).

\begin{tabular}{lr}
\hline Market Shares & Average \\
\hline Lit Book & $54.94 \%$ \\
Dark Pools and SI & $3.28 \%$ \\
Off-Book & $41.78 \%$ \\
Total & $100.00 \%$ \\
\hline
\end{tabular}

post-MiFID period. An increase in the FFI indicates a fragmentation of trading across multiple venues, and as such, any firm wishing to effectively trade that security must be able to execute across more venues. Once a stock's FFI exceeds two, the liquidity in that stock has fragmented to the extent that it no longer belongs to its originating venue.

As we can observe in Fig. 1, there is a significant evolution of the FFI for the CAC40 Firms in the post-MiFID period for our sample since 2007. The FFI in the post-MiFID period exceeds 2. This means that at least two markets are needed to rebuild liquidity. In our analysis, we find an FFI of more than two for our sample in the post-MiFID context, meaning that at least two markets are needed to rebuild liquidity. This result confirms the spatial fragmentation of markets.

Moreover, in Table 3, we observe that the NYSE Euronext Paris, BATS and Chi-X Europe are the three most important markets for our sample in terms of Lit trading, which confirms the importance of the Lit market in France and in the UK for the French CAC40 stocks.

However, even in the presence of a spatially consolidated market, a risk of temporal fragmentation may remain. The temporal fragmentation of the order flow is defined by Schwartz (2010) as the order flow fracturing because in a continuous trading environment, the orders can fail to meet simply because they arrive at the market at different moments in time.

Slicing large orders can accentuate this type of fragmentation and may have impacts on the price discovery process and market intra-day volatility. We estimate the temporal fragmentation by computing the frequency of transactions, which is a proxy of temporal fragmentation and price discovery activity. Our proxy is the average number of transactions per stock per month for our sample.

Table 4 reports the average number of transactions per month before and after the implementation of MiFID for our sample. In 2006, the monthly average number of transactions was around 100000 and in 2012-2013, it rises to 200000 transactions per month. This result confirms the existence of an accentuated temporal fragmentation.

\subsection{Effect of fragmentation on short-term volatility and market efficiency}

\subsubsection{Trade-based market efficiency}

Next, we address the issue of relationship between fragmentation and market efficiency. For this purpose, we use the normalized volatility ratio developed by Ozenbas et al. (2002) and Ozenbas et al. (2011). This ratio captures the fact that, in an efficient market, prices should be approximated by a random walk ${ }^{5}$ because efficient markets are not predictable. We compute the normalized volatility ratio at market opening and at closing, and from the market opening to the market closing. Our analysis focuses on two sub-periods: from January 2006 to December 2006 and from May 2012 to May 2013. This gives us confidence that our results are not related to a

\footnotetext{
${ }^{5}$ Hasbrouck and Schwartz (1988) and Ozenbas et al. (2002) underline that for a random walk, variance increases linearly with time, and hence, volatility (standard deviation) for a random walk increases linearly with the square root of time. However, when returns are serially correlated (as with the case of mean reversion), the linear relationship is perturbed. When share prices follow a random walk, a straightforward relationship exists between half-hour volatility and one-day volatility: the variance of the log of price changes for a one-day interval is seventeen times the average half-hour price change. For the empirical measure of volatility, we use the standard deviation of the log of price changes, so the one-day volatility measure would be the square root of 17 times the half-hour volatility measure.
} 


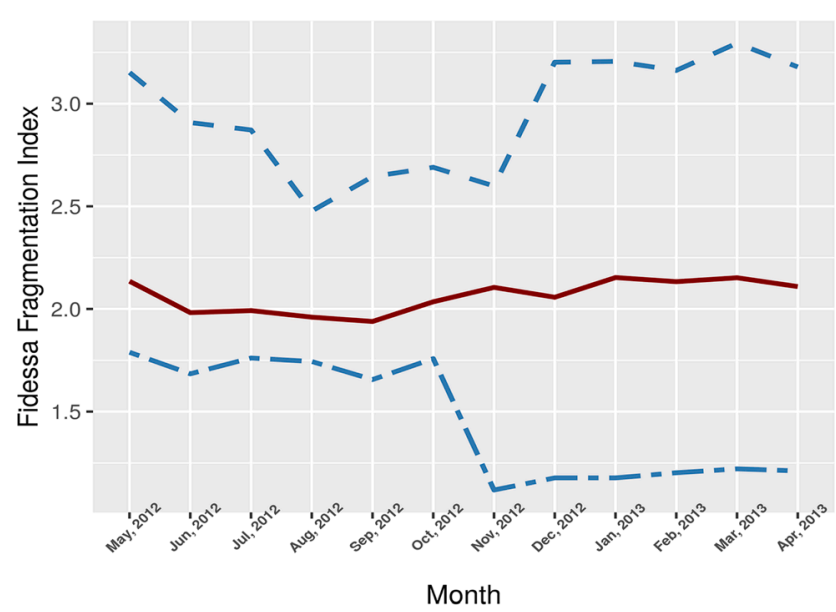

Fig. 1. Evolution of the Fidessa Fragmentation Index (FFI) for the CAC40 Firms in the post-MiFID environment (May 2012-April 2013). Red solid curve shows the means, blue dashed curves show minimum and maximum values.

Table 3

Evolution of market shares for the Lit market (percentage) for the CAC40 firms in the pre- (2006) and post-MiFID environment (May 2012-April 2013). Spatial fragmentation across different alternative venues is available since 2007 with the implementation of MiFID in 2007.

\begin{tabular}{|c|c|c|c|c|}
\hline \multicolumn{5}{|l|}{ Lit market } \\
\hline & \multicolumn{2}{|c|}{ Pre-MiFID Period } & \multicolumn{2}{|c|}{ Post-MiFID Period } \\
\hline & 2006 & Dec 2012 & Feb 2013 & Ap 2013 \\
\hline NYSE Euronext Paris & $100 \%$ & $34.06 \%$ & $38.09 \%$ & $36.26 \%$ \\
\hline BATS Chi-X CXE & Non Available & $10.42 \%$ & $11.93 \%$ & $11.76 \%$ \\
\hline Turquoise & Non Available & $3.33 \%$ & $5.07 \%$ & $5.01 \%$ \\
\hline BATS Chi-X BXE & Non Available & $2.17 \%$ & $2.41 \%$ & $1.97 \%$ \\
\hline Equiduct & Non Available & $0.88 \%$ & $0.92 \%$ & $0.73 \%$ \\
\hline Others & Non Available & $0.79 \%$ & $0.65 \%$ & $0.20 \%$ \\
\hline Total & $100 \%$ & $50.86 \%$ & $59.06 \%$ & $55.58 \%$ \\
\hline
\end{tabular}

Table 4

Evolution of temporal fragmentation for the CAC40 Firms before (from January 2006 to December 2006) and after (from May 2012 to April 2013) the implementation of MiFID, based on the average number of transactions per month.

\begin{tabular}{llll}
\hline Average monthly number of transactions & & & \\
January 2006 & 97870.40 & May 2012 & 201102.90 \\
February 2006 & 93112.73 & June 2012 & 211.00 \\
March 2006 & 106139.63 & July 2012 & 195008.23 \\
April 2006 & 92507.43 & August 2012 & 145448.93 \\
May 2006 & 109272.43 & September 2012 & 178659.17 \\
June 2006 & 108944.07 & October 2012 & 172857.83 \\
July 2006 & 79395.97 & November 2012 & 142905.77 \\
August 2006 & 83134.60 & December 2012 \\
September 2006 & 81817.23 & January 2013 \\
October 2006 & 90182.27 & February 2013 \\
November 2006 & 92939.43 & March 2013 \\
December 2006 & 82629.53 & April 2013 \\
Mean & 93162.14 & Mean & 139788.53 \\
\hline
\end{tabular}

particular calendar period.

According to Ozenbas et al. (2002), if we assume an eight-hour trading day and a half-hour measurement interval, the price change over any day is the sum of sixteen price changes (one for each of the sixteen half-hour periods that comprise the day). Alternatively stated, the price change over a day is sixteen times the average half-hour price change. Is the variance of one-day price change also sixteen times the average half-hour variance? It depends.

For a random walk, variance increases linearly with time and, hence volatility (standard deviation) for a random walk increases linearly with the square root of time. When the returns are serially correlated (as is the case with mean reversion), the linear relationship is perturbed. The volatility for each market and for each half-hour segment in the day is computed as the equally weighted average volatility across all stocks in our sample for a given trading venue and for a given interval. The reported volatilities are then 
normalized by dividing them by the average of the volatilities from the second half-hour segment to the second-to-last half-hour segment for each stock and each month. Therefore, the reported volatilities are scaled by dividing them by the mean-midday volatilities, which constitute the normalized volatility ratio per month for each stock. When the normalized volatility ratios are greater than unity, it reflects the relative inefficiency of prices for the trading at market opening, at the closing periods or from market opening to market closing in comparison to the average value for the midday periods. ${ }^{6}$

Figs. 2 and 3 represent a monthly dynamic of the Normalized Volatility Ratios. We calculate returns over each interval based on the transaction prices at the beginning and ending of each interval. We calculate returns over each interval based on the transaction prices ${ }^{7}$ at the beginning and ending of each interval.

We report a U-shaped intra-day volatility pattern at the individual stock level with high variability between the CAC40 firms for the transaction prices, with a high volatility spike for the first half-hour of trading on the NYSE Euronext Paris. This spike is significant on average before and after the implementation of MiFID and it is about two times larger compared to other periods (excluding the opening and the closing half-hour periods) on NYSE Euronext Paris. We add this smile in Fig. 4 to illustrate what we mean by a volatility smile for Vivendi (FR0000127771) in September 2012.

However, this short-term price volatility is particularly amplified after the implementation of MiFID. Table 5 reveals that volatility ratios differ significantly from unit (with 95\% level of confidence) for the first half-hour period on NYSE Euronext Paris.

For the Pre-MiFID period in 2006, on average, the results in Table 5 should be interpreted as the fact that volatility for the first halfhour of trading is $91 \%$ higher on average than that of the midday half-hour volatilities in 2006. For the Post-MiFID in 2012-2013, it is 95\% higher compared to the similar time intervals in the middle of the day. The amplified volatility and the relative inefficiency of price determination at market openings can be attributed to the complexity of price discovery following a period of non-trading, to the relatively heavy information releases, to the misestimation of true equilibrium value at the opening of the day (see Ozenbas et al. (2011)). Thus, a spike in the first half-hour would be an inverse measure of market quality and price efficiency.

The normalized volatility ratio for the closing session ${ }^{8}$ is also amplified but less than that for the opening session. The results in Table 5 show that volatility in the last half-hour of trading is $13.5 \%$ higher compared to the average of the midday half-hour volatilities in 2006, and $0.025 \%$ higher in 2012-2013. Amplified volatility at market closing reflects the difficulty to absorb a price pressure coming from traders trying to execute their orders before the overnight period (Ozenbas et al. (2002)). After the implementation of MiFID, closing-session volatility ratio is close to unity for most of fragmented stocks, hence we can conclude that price dynamic is close to a random walk at that period. These results provide some evidence of the positive effect of market fragmentation on trade-based market efficiency at the closing period.

Next, we pay a particular attention to intra-day continuous trading volatility dynamics. We find that open-to-close ratios are largely higher than unity before and after the implementation of the MiFID. Table 5 shows that the normalized open-to-close volatility ratios are 4.836 on average in the post-MiFID environment. It means that trending predominates over the day (Ozenbas et al., 2002). Ozenbas et al. (2002) show that the significant difference from the unity can be due to price dislocations driven by one of four market factors (spreads, market impact, dynamic price discovery and momentum trading) that have not been corrected by the price reversals occurred by the end of the trading day. The price reversal may occur on several days and intra-day trend may predominate over a longer period. This result may also be linked to the practices regarding news releases. ${ }^{9}$ We can conclude that intra-day trends are particularly strong and the risk of price dislocation remains significant in a fragmented environment after the implementation of the MiFID.

Similarly to Gresse (2017), we achieved a difference analysis between the pre-/post-MiFID periods. Choosing a post-MiFID period in 2012/2013 has the disadvantage of introducing a potential time trend bias in the comparison of Normalized Volatility Ratios (NVR). This is overcome by a difference test and by a multivariate test which controls for the determinants of NVR and thus captures long-term time effects through those factors. The pre-MiFID period of 2006 is characterized by the absence of fragmentation because the increase of fragmentation in France has begun with the implementation of MiFID in 2007. The post-MiFID monthly period in 2012-2013 comes after the launch of all MTFs considered in the study and is characterized by significant levels of fragmentation (The FFI Index is above 2).

T-tests are then conducted on the differences between mean NVRs variations for the tested samples. Results are reported in Table 6 . In $2012 / 2013$, the normalized volatility ratios for the closing and the open-to close periods are significantly different from 2006. Despite the existence of a significant fragmentation in the post-MiFID period, the normalized volatility ratios approach unity at the closing period through the trade activity of the day, representing an increase in efficiency in the post-MiFID context. This point is particularly important because most investors want prices that are efficient at the end of the day when mutual fund inflows and redemptions are settled. Moreover, in the current fragmented market, it is particularly important for the Alternative markets, such as BATS and Chi-X, as they use the closing price on the Regulated Market Euronext Paris as a reference price. However, concerning the open-to-close ratios, we remark that the intra-day trending predominates more in the post-MiFID context.

\footnotetext{
${ }^{6}$ This analysis is repeated using a variety of time spans. The conclusions remain the same for different time intervals. Hence, we report the more standard 30-minute interval in the paper, similarly to O'Hara and Ye (2011).

${ }^{7}$ Unfortunately, the transaction prices were not available for BATS and Chi-X. If news is public knowledge, prices may change without trading (see Brogaard and Riordan (2019)). Consequently, for the comparison across the three markets, we base our analysis on the spread midpoint rather than the transaction prices. This analysis is available in the next section.

${ }^{8}$ We take into account the last price of the trading session for the last interval.

${ }^{9}$ Similarly to Ozenbas et al. (2011), we limit our analysis to the intra-day level.
} 


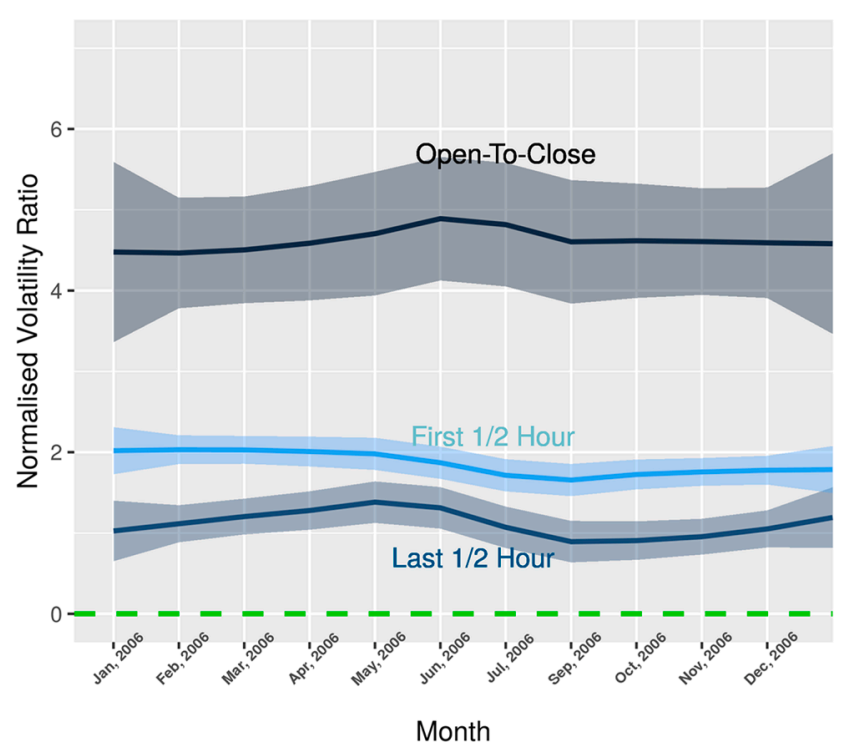

Fig. 2. Monthly evolution of the normalized Volatility Ratio for the CAC40 Index Stocks in 2006 on NYSE Euronext Paris based on the transaction prices. Curves represent median of ratios of individual stocks for respective periods of day, the grey areas around each curve delimit the 1st and 3rd quantiles.

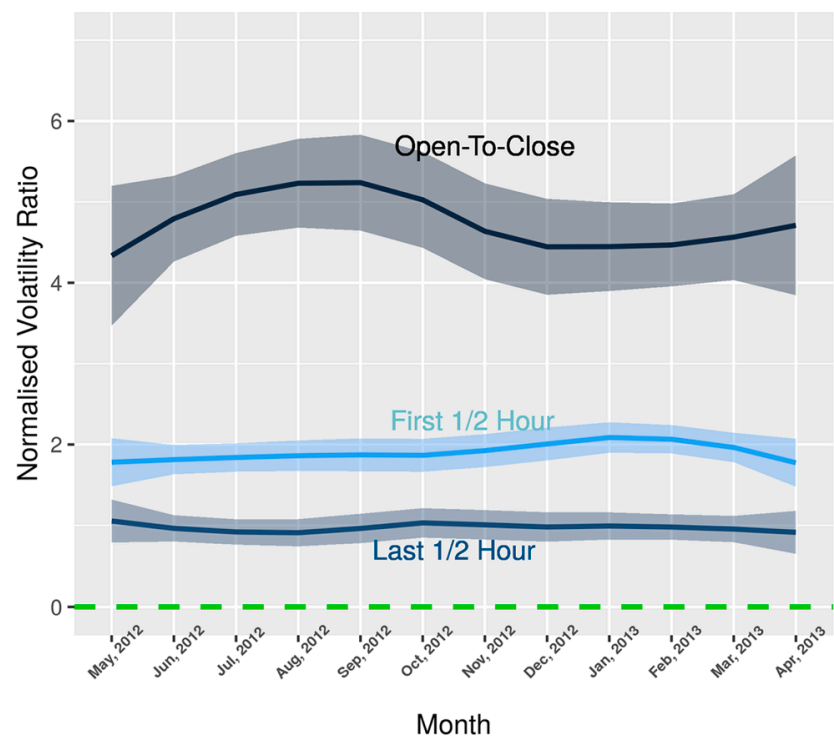

Fig. 3. Monthly evolution of the normalized Volatility Ratio for the CAC40 Index Stocks in 2012-2013 on NYSE Euronext Paris based on the transaction prices. Curves represent median of ratios of individual stocks for respective periods of day, the grey areas around each curve delimit the 1st and 3rd quantiles.

As a complement to univariate tests, we run fixed-effects panel regressions of monthly average measures of normalized volatility ratios. Similarly to Gresse (2017), given that post-MiFID periods do not immediately follow the pre-MiFID period, this simple multivariate test is essential to check that changes in normalized volatility ratios, such as volume, volatility, and price level, are not driving the univariate test's findings. Those factors are controlled in the following model:

$$
\log \left(\mathrm{NVR}_{\mathrm{im}}\right)=\alpha_{\mathrm{i}}+\alpha_{1} \sigma_{\mathrm{im}}+\alpha_{2} \ln \mathrm{V}_{\mathrm{im}}+\alpha_{3} \frac{1}{\mathrm{P}_{\mathrm{im}}}+\alpha_{05 / 12} \mathrm{~B}_{\mathrm{May} 12}+\cdots+\alpha_{\frac{04}{13}} \mathrm{~B}_{\mathrm{April13}}+\varepsilon_{\mathrm{im}}
$$

where $\mathrm{NVR}_{\mathrm{im}}$ is the average normalized volatility ratio for stock i over month $\mathrm{m}$ at the opening or at the closing; $\sigma_{\text {im }}$ measures volatility by the standard deviation of logarithmique daily closing returns for stock i over month $\mathrm{m}$; $\ln \mathrm{V}_{\mathrm{im}}$ is the logarithm of the total trading volume in euros for stock i over month $\mathrm{m} ; \frac{1}{\mathrm{P}_{\mathrm{im}}}$ is the reciprocal of the average primary market's closing price of stock i during month m; 


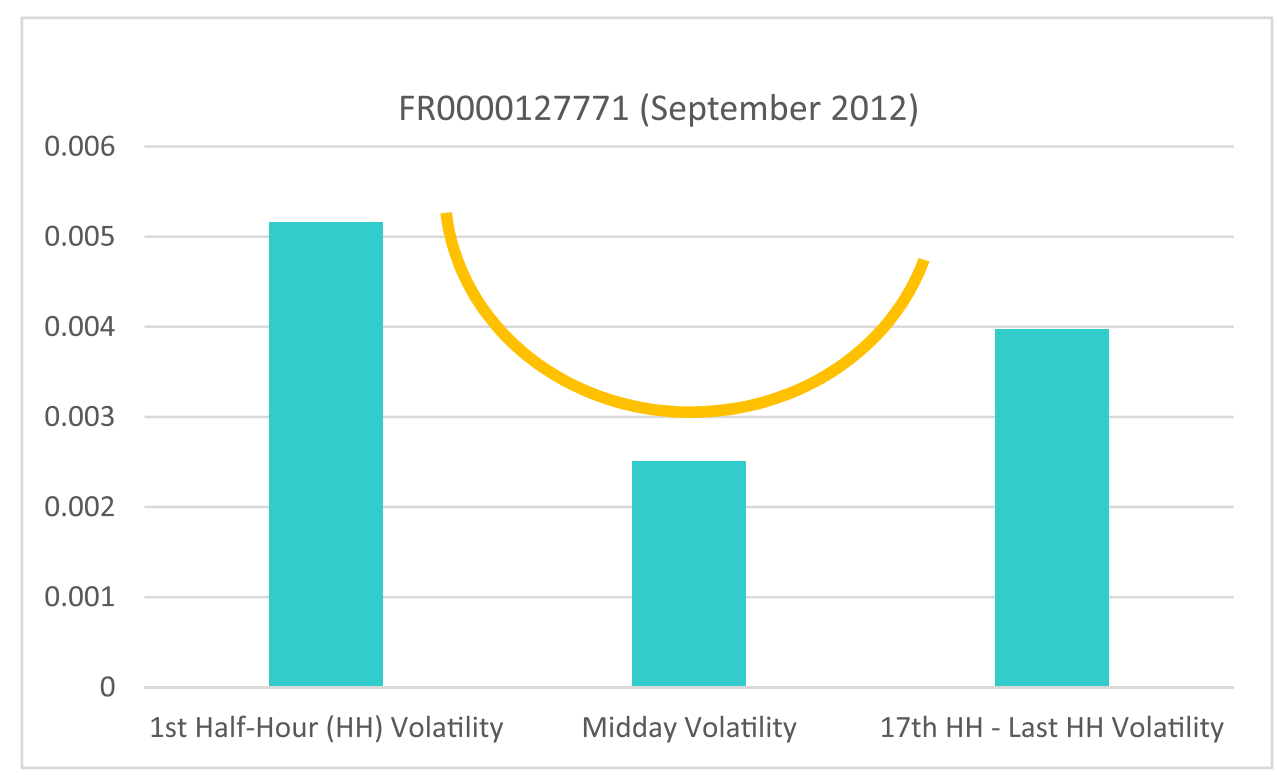

Fig. 4. We add this smile figure to illustrate what we mean by a volatility smile for Vivendi (FR0000127771) in September 2012.

Table 5

Evolution of monthly normalised volatility ratios for the CAC40 Firms before (from January 2006 to December 2006) and after the implementation of MiFID (from May 2012 to April 2013) for the transaction prices on NYSE Euronext Paris.

\begin{tabular}{|c|c|c|c|c|c|c|c|}
\hline & First Half-Hour & Last Half-Hour & Open-to-Close & & First Half-Hour & Last Half-Hour & Open-to-Close \\
\hline January 2006 & 2.228 & 1.180 & 4.865 & May 2012 & 1.782 & 1.004 & 4.328 \\
\hline February 2006 & 1.848 & 1.131 & 4.767 & June 2012 & 1.777 & 1.087 & 4.781 \\
\hline March 2006 & 2.004 & 1.093 & 4.543 & July 2012 & 1.912 & 0.803 & 4.772 \\
\hline April 2006 & 2.161 & 1.174 & 4.176 & August 2012 & 1.881 & 1.017 & 4.972 \\
\hline May 2006 & 2.170 & 1.542 & 5.377 & September 2012 & 2.074 & 1.085 & 5.345 \\
\hline June 2006 & 1.795 & 1.233 & 4.217 & October 2012 & 2.198 & 1.130 & 5.108 \\
\hline July 2006 & 1.812 & 1.069 & 4.797 & November 2012 & 1.748 & 0.965 & 4.995 \\
\hline August 2006 & 1.644 & 0.875 & 4.242 & December 2012 & 2.010 & 1.082 & 4.142 \\
\hline September 2006 & 2.017 & 1.046 & 4.286 & January 2013 & 2.082 & 0.933 & 4.483 \\
\hline October 2006 & 1.784 & 1.010 & 4.195 & February 2013 & 2.019 & 1.139 & 5.120 \\
\hline November 2006 & 1.756 & 1.119 & 4.283 & March 2013 & 2.007 & 1.153 & 4.796 \\
\hline December 2006 & 1.721 & 1.146 & 4.481 & April 2013 & 1.947 & 0.902 & 5.189 \\
\hline Mean & 1.912 & 1.135 & 4.519 & Mean & 1.953 & 1.025 & 4.836 \\
\hline
\end{tabular}

$\mathrm{B}_{\text {May12 }}$ up to $\mathrm{B}_{\mathrm{April13}}$ are binary variables equal to one in the month concerned and set to zero otherwise. $\alpha_{1}, \alpha_{2}, \alpha_{3}$ are the coefficients of the control variables. $\alpha_{05 / 12} \ldots \alpha_{\frac{04}{13}}$ denote the respective coefficients of $\mathrm{B}_{\mathrm{May} 12} \ldots \mathrm{B}_{\mathrm{April13}}$. The panel regressions are run with a fixed effect per stock $\left(\alpha_{\mathrm{i}}\right)$ and with data covering the two-years of data (2006 and 2012/2013). Dummies $\mathrm{B}_{\text {May12 ... }} \mathrm{B}_{\text {April13 }}$ play the role of fixed effects per month. The estimates of the regressions are reported in Table 7 . The control variables are not significant and we observe significant decreases for the NV ratios at the closing in the post-MiFID environment that are consistent with the difference-indifferences findings.

\subsubsection{Quote-based market efficiency}

After studying normalized volatility ratios for the transaction prices on the RM, we would like to compare this metric across the NYSE Euronext Paris, BATS and Chi-X Europe for December 2012, February 2013 and April 2013. These months correspond to a high level of fragmentation. For this purpose, we compute the normalized volatility ratios based on the spread midpoint at the beginning and ending of each interval. ${ }^{10}$ Ozenbas et al. (2002) conduct their study trades but recognize that it is also important to use the spread midpoints to compare markets because if news is public knowledge, prices may change without trading (see also Brogaard and Riordan, 2019).

Moreover, this approach allows us to compare the proxy of price efficiency for the trading and the quoting activity on the NYSE Euronext Paris. First, Table 8 shows that the normalized volatility ratios are higher for the quoting activity than for the trading activity

$\overline{10}$ We use the midpoint of the quotes defined by the arithmetic mean of the two best limits. 
Table 6

This table reports averages of fragmentation indices, volatility measures and normalized volatility ratios (NVR), by month and by sample, as well as statistics on the differences in the NVR measures between the non-fragmented pre-MiFID period (2006) and each fragmented post-MiFID period in 2012-2013. The second column gives a fragmentation index calculated by taking the inverse of the sum of the squares of market shares, the Fidessa Fragmentation Index (FFI). The third column is the Volatility of the index daily closing returns during the month. Average normalized volatility ratios (NVR) are measured in the primary market Euronext Paris. For each month, the "Mean" line reports the means of NVR measure; the "Diff. from 2006" line reports their mean differences between 2006 and the considered month. ***,**,** means that the difference in consideration is statistically different from zero according to a $t$-test at the $1 \%, 5 \%$, or $10 \%$ level respectively.

\begin{tabular}{|c|c|c|c|c|c|c|c|}
\hline & \multirow[t]{2}{*}{ Index Volatility } & \multirow[t]{2}{*}{ Index Fragmentation (FFI) } & & & \multicolumn{3}{|c|}{ Normalized volatility ratio } \\
\hline & & & & & First Half-Hour & Last Half-Hour & Open-to-Close \\
\hline \multirow[t]{25}{*}{ CAC40 } & & 1 & 2006 & Mean & 1.91 & 1.13 & 4.52 \\
\hline & 0.063 & 2.14 & May 2012 & Mean & 1.78 & 1.00 & 4.33 \\
\hline & & & & Diff. from 2006 & -0.13 & $-0.13^{* * *}$ & -0.19 \\
\hline & 0.071 & 1.98 & June 2012 & Mean & 1.78 & 1.09 & 4.78 \\
\hline & & & & Diff. from 2006 & $-0.13^{*}$ & -0.05 & 0.26 \\
\hline & 0.071 & 1.99 & July 2012 & Mean & 1.91 & 0.80 & 4.77 \\
\hline & & & & Diff. from 2006 & 0.00 & $-0.33^{* * *}$ & $0.25^{* *}$ \\
\hline & 0.060 & 1.96 & August 2012 & Mean & 1.88 & 1.02 & 4.97 \\
\hline & & & & Diff. from 2006 & -0.03 & $-0.11^{* * *}$ & $0.45 * *$ \\
\hline & 0.064 & 1.94 & September 2012 & Mean & 2.07 & 1.09 & 5.34 \\
\hline & & & & Diff. from 2006 & $0.16^{*}$ & -0.05 & $0.48^{* * *}$ \\
\hline & 0.054 & 2.04 & October 2012 & Mean & 2.20 & 1.13 & 5.11 \\
\hline & & & & Diff. from 2006 & $0.29 * *$ & -0.01 & $0.59 * * *$ \\
\hline & 0.049 & 2.1 & November 2012 & Mean & 1.75 & 0.96 & 4.99 \\
\hline & & & & Diff. from 2006 & $-0.16^{*}$ & $-0.17^{* * *}$ & $0.47^{* * *}$ \\
\hline & 0.022 & 2.06 & December 2012 & Mean & 2.01 & 1.08 & 4.14 \\
\hline & & & & Diff. from 2006 & 0.10 & -0.05 & $-0.38^{* * *}$ \\
\hline & 0.033 & 2.15 & January 2013 & Mean & 2.08 & 0.93 & 4.48 \\
\hline & & & & Diff. from 2006 & 0.17 & $-0.20^{* * *}$ & -0.04 \\
\hline & 0.068 & 2.13 & February 2013 & Mean & 2.02 & 1.14 & 5.12 \\
\hline & & & & Diff. from 2006 & 0.11 & 0.00 & $0.6^{* * * *}$ \\
\hline & 0.042 & 2.15 & March 2013 & Mean & 2.01 & 1.15 & 4.80 \\
\hline & & & & Diff. from 2006 & 0.09 & 0.02 & 0.28 \\
\hline & 0.065 & 2.11 & April 2013 & Mean & 1.95 & 0.90 & 5.19 \\
\hline & & & & Diff. from 2006 & 0.04 & $-0.23^{* * *}$ & $0.67^{* * *}$ \\
\hline
\end{tabular}

Table 7

This table reports the estimates of panel regressions of NV ratio at the opening and at the closing run with a fixed effect per stock and monthly dummies standing for May 2012 to April 2013, respectively denoted BMay12, ..., and BApril13. The observation period includes those 12 post-MiFID months plus the pre-MiFID year of 2006. Variables used in the regressions are monthly observations per stock for 30 equities (CAC-40 components). NVR is expressed is taken in logarithm. The set of control variables includes volatility measured by the standard deviation of closing returns, volume measured by the logarithm of the total euro trading volume; and price level measured by the reciprocal of the average primary market's closing price. $* * *, * *, *$ indicates statistical significance at the $1 \%, 5 \%$, or $10 \%$ level respectively. T-statistics are provided in brackets.

\begin{tabular}{|c|c|c|c|c|c|c|}
\hline \multirow[b]{2}{*}{ Variable } & \multicolumn{3}{|c|}{$\begin{array}{l}\text { One-stage panel regressions of monthly normalized volatility ratios at } \\
\text { the opening around MiFID }\end{array}$} & \multicolumn{3}{|c|}{$\begin{array}{l}\text { One-stage panel regressions of monthly normalized volatility ratios at } \\
\text { the closing around MiFID }\end{array}$} \\
\hline & Estimation & T-Statistics & $\operatorname{Pr}>|t|$ & Estimation & T-Statistics & $\operatorname{Pr}>|t|$ \\
\hline BMay12 & -0.03925 & -1.92 & 0.0547 & -0.0567 & -2.76 & $0.0059 * * *$ \\
\hline BJune12 & -0.04096 & -1.99 & $0.0466 * *$ & -0.01955 & -0.94 & 0.3451 \\
\hline BJuly12 & 0.000395 & 0.02 & 0.9843 & -0.15021 & -7.43 & $<0.0001^{* * *}$ \\
\hline BAug12 & -0.00485 & -0.24 & 0.8103 & -0.04942 & -2.43 & $0.0153^{* *}$ \\
\hline BSep12 & 0.028803 & 1.45 & 0.1488 & -0.02922 & -1.46 & 0.1458 \\
\hline BOct12 & 0.073604 & 3.76 & $0.0002^{* * *}$ & -0.00279 & -0.14 & 0.8875 \\
\hline BNov12 & -0.03751 & -1.89 & 0.0592 & -0.06441 & -3.22 & $0.0013^{* * *}$ \\
\hline BDec12 & 0.036888 & 1.83 & 0.0682 & -0.0022 & -0.11 & 0.9138 \\
\hline BJan13 & 0.068106 & 3.48 & $0.0005^{* * *}$ & -0.07097 & -3.6 & $0.0003^{* * *}$ \\
\hline BFeb13 & 0.01668 & 0.84 & 0.4006 & -0.00107 & -0.05 & 0.9574 \\
\hline BMarch13 & 0.021979 & 1.12 & 0.2618 & -0.01813 & -0.92 & 0.358 \\
\hline BApril13 & -0.00755 & -0.38 & 0.7059 & -0.10466 & -5.2 & $<0.0001 * * *$ \\
\hline
\end{tabular}

on the NYSE Euronext Paris. We also find a U-shaped volatility pattern for the quoting activity that is much more accentuated than that for transaction prices. These findings can be explained that if news is a public knowledge, quotes may change rapidly without resulting in a trade in order-driven market.

Handa and Schwartz (1996) underline that the use of limit orders involves the risk of an adverse information event that can trigger an undesirable execution and the risk of favorable news that can result in a desirable execution not being obtained. Moreover, the lack of limit orders (reduced order book depth) can lead to amplified short-term price swings. It can be the reason why we obtain higher 
Table 8

Evolution of the normalised volatility ratios on average for the CAC40 Firms after the implementation of MiFID (in December 2012, February 2013 and April 2013) for the spread midpoint on NYSE Euronext Paris, BATS and Chi-X Europe.

\begin{tabular}{|c|c|c|c|c|}
\hline \multicolumn{5}{|l|}{ Euronext Paris } \\
\hline $\mathrm{NV}$ ratios & December 2012 & February 2013 & April 2013 & Mean \\
\hline First half-hour & 6,603 & 5,433 & 9,721 & 7,252 \\
\hline Last half-hour & 5,235 & 3,550 & 5,836 & 4,874 \\
\hline Open-to-close & 5,855 & 4,551 & 6,822 & 5,743 \\
\hline \multicolumn{5}{|l|}{ BATS Europe } \\
\hline & December 2012 & February 2013 & April 2013 & Mean \\
\hline First half-hour & 5,864 & 4,808 & 4,397 & 5,023 \\
\hline Last half-hour & 1,577 & 1,604 & 0,812 & 1,331 \\
\hline Open-to-close & 7,413 & 6,956 & 5,767 & 6,712 \\
\hline \multicolumn{5}{|l|}{ Chi-X Europe } \\
\hline & December 2012 & February 2013 & April 2013 & Mean \\
\hline First half-hour & 5,259 & 3,770 & 4,730 & 4,586 \\
\hline Last half-hour & 1,409 & 1,373 & 0,922 & 1,235 \\
\hline Open-to-close & 6,708 & 6,142 & 6,178 & 6,343 \\
\hline
\end{tabular}

quote-based normalized volatility ratios compared to those computed based on trade information.

Another possible explanation of the differences in quote-based and trade-based metrics can be found in Baruch and Glosten (2013), who explore the possibility that limit-order traders manage their undercutting exposure by rapidly cancelling their quotes and replacing them with new randomly chosen ones, thereby mitigating their undercutting risk by undoing transparency and playing the liquidity provision game. Furthermore, Colliard and Foucault (2012) show that lowering trading costs through an increase in competition can induce investors to post limit orders with a smaller execution probability. Not all quotes are translated into trades, which may affect short-term volatility.

We then find that the U-shaped intra-day volatility pattern is higher for the NYSE Euronext Paris (RM) than for the BATS and Chi-X Europe (MTFs). The normalized volatility ratios are particularly high for RM compared to alternative platforms MTFs during closing session. The half-hour intra-day volatility patterns for all three markets are displayed in Table 8. We observe high volatility spikes at market opening for three studied markets. Our results are in line with those of Ozenbas et al. (2002) that after the implementation of the MiFID, at each opening, information that has been released since the previous closing must be incorporated into prices. The conflicting opinions held by traders (represented by high buy-sell imbalances) must be resolved quickly and aligned with the consensus values in an orderly manner with a high degree of accuracy.

The MTFs (BATS and Chi-X Europe) are more efficient on average for quoting activity during the opening and closing periods than the RM (NYSE Euronext Paris). This phenomenon may derive from the particular attributes like rulebooks and trading hours of each trading venue. The MTFs have invested heavily in fast information technology to attract order flows through algorithmic trading and statistical arbitrage. To make their platforms more attractive for institutional HFTs, the MTFs employ a minimal headcount to reduce costs; apply maker/taker pricing; pay members to trade on the platform as long as the trades add liquidity rather than takes; and develop trading incentives, often called jump-balls, in which stakes are given to trading members in return for volume traded. Lastly, the MTFs usually operate a smart order router (SOR) that optimizes order execution by navigating the orders out of a traffic jam in one particular market queue to other external trading platforms or splitting block orders smartly to achieve the most effective execution.

This difference in technology and the type of investors trading on the different markets may also explain the differences in normalized volatility ratios between the RM and the MTFs. ${ }^{11}$ Finally, in the absence of a consolidated tape for the European market and in the presence of a spatial fragmentation of stock market orders, the risk is that the MTFs can offer rapid execution at low commissions by taking advantage of the price discovery provided by the main market center (the RM) (see Clapham and Zimmermann (2016)). This price leader-follower relationship may have an impact on the short-term volatility, explaining the less accentuated volatility for the MTFs.

\subsection{Causes of price inefficiency at market opening and closing in the post-MiFID context}

In this subsection we try to clarify some reasons of the significant volatility spikes at the market opening and closing on the NYSE Euronext Paris. We conduct a multivariate analysis for 2006 (the pre-MiFID period) and for 2012-2013 (the post-MiFID period) to take

\footnotetext{
11 The NYSE Euronext Paris has always relied on a transparent pre-opening phase and call auctions to open continuous markets, and the NYSE Euronext Paris benefits from a closing call auction. This is not the case for the BATS and Chi-X Europe for our period of study. The BATS and Chi-X automated trading schedule for active listed instruments is from 08:00 am (the official market opening for the continuous session) to 16:30 in UK time (the official market closing for the end of the continuous trading session), without any official opening and closing auctions on the MTFs. BATS Chi-X chooses the reference price for market closing. The continuous trading session on Euronext Paris is from 09:00 am to 05:30 pm (in France time).
} 
into account the increased level of fragmentation after the implementation of the MiFID. ${ }^{12}$ The regression was run independently of the stock capitalization sizes, given that all stocks included in the CAC40 Index have large capitalizations.

The first half-hour normalized volatility ratio as a proxy for price efficiency at market opening (see Section 4.2.1) is the dependent variable for each stock and each calendar year. ${ }^{13}$ In addition, the last half-hour normalized volatility ratio is also the dependent variable in the post-MiFID regression to study the behavior of traders at the closing.

Regression analysis before the implementation of MiFID. We run the regression based on the data for the year 2006. The normalized trade-based volatility ratio for the first half-hour on NYSE Euronext Paris is considered as the dependent variable (NV Ratio at the opening). Similar to Ozenbas et al. (2011), we expect a positive relationship between the trading activity and the normalized volatility ratio of first half-hour for the large stocks.

Consequently, the following parameters are considered as explanatory variables: the logarithm of monthly average price, the logarithm of monthly average volume, the monthly average volatility (the standard deviation of open-to-close daily returns for each stock per month), the logarithm of the opening half-hour number of trades for each stock per month, and the logarithm of the opening half-hour volume estimated for each stock per month. These variables are also used in Ozenbas et al. (2011), and O'Hara and Ye (2011).

The multivariate results of our regression analysis with the parameter estimates and the t-statistics for the pre-MiFID period are available in the Table 9. We observe a positive and significant relationship between the normalized volatility ratio for the first halfhour and the monthly average volatility. The monthly average volatility used as a control variable is significant in 2006 and positively related to our dependent variable. This indicates a difficult price discovery process for the more volatile stocks during year 2006, just before the great financial crisis.

This result shows also that price inefficiencies at the opening are greater for the more volatile stocks. A similar result was found by Ozenbas et al. (2011) during year 2000, given the stock market crash of 2000. Furthermore, there is a positive and significant relationship between the normalized volatility ratio and the logarithm of monthly average half-hour number of trades at the opening. This result shows that an increased price discovery activity, defined as a higher number of trades, is positively related to our dependent variable.

Regression analysis after the implementation of MiFID. To run the regression for the year 2012-2013, the dependent variable is the normalized volatility ratio for the first half-hour and for the last-half hour on the NYSE Euronext Paris based on the transaction prices, where $s$ is the $s^{\text {th }}$ stock during the $m^{\text {th }}$ month and the $n^{\text {th }}$ year. This allows us to study the determinants at the opening and at the closing, which are two sensitive periods.

The closing is particularly important because it serves as a point of reference for the alternative markets, such as BATS and Chi-X, and the different market participants. It is important to have prices that are efficient at the end of the day when mutual fund inflows and redemptions are settled. This extended list of variables is also used in Ozenbas et al. (2011), O'Hara and Ye (2011), and Gresse (2017). For the multivariate analysis of the post-MiFID period, we use variables to consider the effect of fragmentation on the price efficiency at market opening. The monthly average FFI, computed for each stock per month, is used in the regression because since the implementation of MiFID, the CAC40 stocks can be exchanged on other Lit markets in addition to the primary RM NYSE Euronext Paris. This parameter gives us an indication of the spatial fragmentation induced by the MiFID between the Lit markets for the same stock.

We also add the monthly average level of off-trading per stock because it is not represented in the FFI, which focuses on the Lit market via electronic order books. Additionally, we use the monthly average level of dark trading for each stock per month.

To take into account the potential impacts of HFTs on price efficiency at market opening or closing, we add the average monthly percentage of HFTs or non-HFTs on the buy side for the first half-hour for each stock or for the last half-hour as explanatory variables (also used by Brogaard et al. (2010) and Aitken et al. (2015)). These parameters faced significant changes after the MiFID and consequently may have significant impact on the short-term volatility and the price efficiency at market opening or closing. We should highlight that this ability to distinguish different traders' profiles is outstanding feature of our database and important added-value of our study. The multivariate results of our regression analysis with the parameter estimates and the t-statistics for the post-MiFID period for the opening and the closing are reported in Table 9.

For the post-MiFID period at the opening, the first half-hour normalized volatility ratio is on average equal to 1.953 , which is higher than one. It means that the prices don't follow a random-walk at the opening. Our findings indicate that price determination is relatively inefficient at market openings.

The volatility spikes for the first half-hour are substantial on Euronext Paris. It is roughly two times the average of the other periods (excluding the opening and the closing half-hour periods).

What accounts for them? At each opening, information that has been released since the previous close must be incorporated into prices. In the process, conflicting opinions held by traders have to be resolved quickly, in an orderly manner, and with a high degree of accuracy. The opens are typically serious periods of high buy/sell orders imbalances that result in opening prices being imperfectly aligned with their consensus value. Any accentuation of first half-hour volatility would not be attributed to news per se (either overnight or in general), but to opening prices not reflecting accurate adjustments to the news.

As such, the accentuated first half-hour price volatility would be evidence of price discovery being a protracted process that extends into, and perhaps beyond, the first half-hour period. For this reason, a spike for the first half-hour would be a particularly meaningful,

\footnotetext{
$\overline{12}$ We use two years of data (2006 and 2012/2013) to assess the significant variables explaining the short-term accentuated volatility at market opening.

${ }^{13}$ Data is winsorized to deal with the heteroskedasticity issues.
} 
Table 9

Multivariate regression analysis (OLS) of normalized volatility ratio during the first half-hour for the pre-MiFID period for NYSE Euronext Paris based on the transaction prices, and during the first- and the last half-hour periods for the post-MiFID period.

For the pre-MiFID period, the variables are: The logarithm of monthly average price is the average trading price for each stock per month, the logarithm of monthly average volume is the average monthly share volume for each stock per month based on the average number of transactions per month and the average quantity exchanged per transaction for each stock per month. The average monthly volatility is the standard deviation of opento-close daily returns for each stock per month, the logarithm of the opening half-hour number of trades is the average number of trades during the first half-hour of trading for each stock per month and the logarithm of the opening half-hour volume is the average trading volume during the first half-hour of trading for each stock per month. ${ }^{* *}=\mathrm{p}<0.05$.

For the post-MiFID period, the multivariate regression analysis (OLS) of the normalized volatility ratio is achieved during the first half-hour and the last half-hour. For the first half-hour and the last half-hour periods, the variables are the following: the average monthly volatility is the standard deviation of open-to-close daily returns for each stock per month. The monthly average price is the average trading price for each stock per month, while the monthly average number of transactions is the average number of transactions for each stock per month. The opening (closing) half-hour number of trades is the average number of trades during the first (last) half-hour of trading for each stock per month, and the logarithm of the opening (closing) half-hour volume is the average trading volume during the first (last) half-hour of trading for each stock per month. The following variables related to fragmentation are defined in Section 2: the FFI is a measure of fragmentation on the Lit market for each stock per month, the monthly average off-trading is the market share that is not on the Lit market, the systematic internalizers or on the dark pools for each stock per month, and the monthly average dark trading is the market share of trading executed on the dark pools for each stock per month. The opening (closing) half-hour percentage of HFTs and the opening (closing) half-hour percentage of non-HFTs are defined by the AMF and are immutable. The classification is based on the median life duration of the orders that are modified or cancelled with the median life duration of all market orders modified or cancelled (i.e., total market modifications or cancellations). The threshold to define an HFT is one second. ${ }^{* *}=\mathrm{p}<0.05$.

\begin{tabular}{|c|c|c|c|c|c|}
\hline \multirow{2}{*}{$\begin{array}{l}\text { Pre-MiFID period } \\
\text { Dependent variable: } \log (\mathrm{NV} \text { Ratio o } \\
\text { first half-hour) }\end{array}$} & & \multicolumn{4}{|l|}{ Post-MiFID period } \\
\hline & & \multicolumn{2}{|c|}{$\begin{array}{l}\text { Dependent variable: Log(NV Ratio of first half- } \\
\text { hour) }\end{array}$} & \multicolumn{2}{|c|}{$\begin{array}{l}\text { Dependent variable: } \log (\mathrm{NV} \text { Ratio of last half- } \\
\text { hour) }\end{array}$} \\
\hline \multicolumn{2}{|l|}{ Number of observations 360} & \multicolumn{2}{|l|}{ Number of observations 360} & \multicolumn{2}{|l|}{ Number of observations 347} \\
\hline \multicolumn{2}{|c|}{ Adj. R2 0,1007 } & \multicolumn{2}{|l|}{ Adj. R2 0,0731 } & \multicolumn{2}{|l|}{ Adj. R2 0,07 } \\
\hline \multicolumn{6}{|c|}{ Estimation of parameters and t-statistic with a significance level of $5 \%$ indicated by ** } \\
\hline \multicolumn{2}{|c|}{$\begin{array}{l}\text { Variable Name Parameter estimate for the first } \\
\text { half-hour }\end{array}$} & \multicolumn{2}{|c|}{$\begin{array}{l}\text { Variable name Parameter estimate for the first- } \\
\text { half hour }\end{array}$} & \multicolumn{2}{|c|}{$\begin{array}{l}\text { Variable name Parameter estimate for the last } \\
\text { half-hour }\end{array}$} \\
\hline Constant & $0,535 * *$ & Constant & $1,147 * *$ & Constant & 0 \\
\hline Log(Monthly average price) & $-0,047$ & Log(Monthly average price) & $-0,031$ & Log(Monthly average price) & 0.054 \\
\hline Monthly volatility & $5,989 * *$ & Monthly volatility & 0,750 & Monthly volatility & -2.041 \\
\hline \multirow[t]{4}{*}{ Log(Monthly volume) } & $-0,054$ & $\begin{array}{l}\text { Log(Monthly average number of } \\
\text { transactions) }\end{array}$ & $-0,223^{* *}$ & $\begin{array}{l}\text { Log(Monthly average number of } \\
\text { transactions) }\end{array}$ & $-0.272^{* *}$ \\
\hline & & Fidessa Fragmentation Index & 0,019 & Fidessa Fragmentation Index & 0.002 \\
\hline & & Monthly average off trading & $-0,051$ & Monthly average off trading & -0.007 \\
\hline & & Monthly average dark trading & 0,268 & Monthly average dark trading & -0.285 \\
\hline $\begin{array}{l}\text { Log(Opening half-hour number of } \\
\text { trades) }\end{array}$ & $0,090^{* *}$ & $\begin{array}{l}\text { Log(Opening half-hour number of } \\
\text { trades) }\end{array}$ & $0,270 * *$ & $\begin{array}{l}\text { Log(Last half-hour number of } \\
\text { trades) }\end{array}$ & $0.289 * *$ \\
\hline \multirow[t]{3}{*}{ Log(Opening half-hour volume) } & $-0,017$ & Log(Opening half-hour volume) & $-0,078$ & Log(Last half-hour volume) & $0.068 * *$ \\
\hline & & $\begin{array}{l}\text { Opening half-hour percentage of } \\
\text { HFTs }\end{array}$ & $-0,290 * *$ & Last half-hour percentage of HFTs & -0.032 \\
\hline & & $\begin{array}{l}\text { Opening half-hour percentage of } \\
\text { non-HFTs }\end{array}$ & 0,057 & $\begin{array}{l}\text { Last half-hour percentage of non- } \\
\text { HFTs }\end{array}$ & 0.066 \\
\hline
\end{tabular}

inverse measure of quality.

In Table 9 with our regression for the post-MiFID period concerning the explanations of the first half-hour normalized volatility ratio, we observe that three variables are significant: the Monthly average number of transactions, the Opening half-hour number of trades and the Opening half-hour percentage of HFTs.

We observe a positive and significant relationship between the opening number of trades and our efficiency metric. This result shows that increased price discovery activity, as evidenced by a higher number of trades, is positively related to our dependent variables.

More-frequent trades at the open are likely to coexist with greater uncertainty about the stock's price that the market is seeking to discover, and thus this variable is a good proxy for increased price discovery activity (in other words, more trades are needed before a relatively stable price is found on heavy-volume days). This result is confirmed by Ozenbas et al. (2011) for the US markets.

Concerning the spatial fragmentation induced by the implementation of the MiFID, the proportion of dark trading and off trading are not significant explanatory variables. Moreover, the FFI is not significant in explaining the accentuated short-term volatility and the price inefficiency at market opening for our large-cap stocks.

Our results do not allow us to establish any significant relationship between the spatial fragmentation and amplified short-term volatility or the price inefficiency at market opening. These results are also confirmed by O'Hara and Ye (2011) for the US equity market and Gresse (2017), who found that neither dark trading nor spatial fragmentation between lit order books is found to harm liquidity in the EU.

Ibikunle et al. (2020) underline that there is a concern that some experienced traders can locate potential arbitrage opportunities since quotes across regulated markets and MTFs are not closely linked due to the absence of trade-through protection. However, 
MiFIDs transparency regime mandates MTFs to disclose trade-related information as close to real time as possible. Ibikunle et al. (2020) postulate that if this transparency regime does disclose sufficient trading information content, then, with a high level of trading fragmentation, information on MTFs can spread to other venues. In this case, liquidity providers could adjust quotes against informed traders, decreasing arbitrage opportunity and short-term profitability for informed traders.

The result of our regression also shows the impacts of the half-hour percentage of high-frequency buyers at market opening on the amplified short-term volatility and price inefficiency at market opening. The higher percentage of active high-frequency buyers at market opening reduces the short-term volatility and improves market efficiency.

This result is consistent with Brogaard et al. (2014), Hasbrouck and Saar (2013), Hendershott et al. (2011) and O'Hara and Ye (2011), showing that increased low-latency activity improves traditional market quality measured by short-term volatility. Our study underlines that it is important not to discourage the presence of HFTs at market opening in the revision of MiFID.

Conrad et al. (2015) show that higher quotation activity is associated on average with price series that more closely resemble a random walk, and significantly lower cost of trading.

For the post-MiFID period at the closing, our results underline that the last-half hour Normalized Volatility (NV) ratio is on average equal to 1.025 , which is close to one. The price process at the closing resembles a random walk. The small volatility spikes at the close results, in part at least, from the price pressures caused by agents cleaning up orders that must be complete within the day, and from traders unwinding positions so as to end the day flat. The closing period is much more efficient after the implementation of the MiFID. In line with Pagano et al. (2013) and Pagano and Schwartz (2003), we find that the closing call auction encourages more efficient price behavior at market closing by controlling price volatility in the continuous market (in the last 30 min of continuous market).

What is the contribution of HFTs to this more efficient price behavior at the closing? To answer to this question, we achieved a regression for the closing periods from $5 \mathrm{pm}$ to $5.30 \mathrm{pm}$ on Euronext Paris to observe the impact of HFTs on the normalized volatility ratios at the closing period. The results of the regression are available in Table 9. We run the same regression than for the NV ratio at the opening. The dependent variable is the normalized volatility ratio at the last half-hour period.

The following variables provide significant information to explain the variability of the dependent variable: $\log$ tran, $\log (\mathrm{aver}-$ agevol/close $30^{\prime}$ ) and the $\log$ (tran/ $30^{\prime}$ close), which is the logarithm of average number of trades during the last half-hour of trading for each stock. The last variable is the most significant. This is consistent with our results at the opening.

In our sample, the percentage of pure HFTs at the closing is on average 23.35 percent, 59.7 percent for the mixed-HFTs and 16.95 percent for the non-HFTs. In terms of results, the classification of traders at the closing has no impact on the normalized volatility ratios at the closing periods at a frequency of half-hour intervals. This result is consistent with the study in Saliba (2020) that provides a closer examination on the behavior of HFTs on Euronext Paris. At the end of the day, HFTs market depth share and HFTs amounts offered decrease rapidly. Indeed, HFTs do not generally hold overnight positions. At the end of the day, HFTs essentially withdraw their orders from the order book.

The study of the AMF (2017) confirms these results. High-frequency traders are important contributors to liquidity during normal market conditions. They are present at the best bid or best offer prices more than $90 \%$ of the time and they represent on average $80 \%$ of the market depth in the order book at the three best price limits. On an intraday basis, they enter the order book gradually and help to reduce the bid ask spread (the difference between the best buy and sale prices) at the beginning of the day, however they clearly reduce their presence in the order book ahead of announcements that are likely to affect share prices. It should be noted that, at the end of the day, the decrease in the HFTs' market share is compounded by a change in non-HFT behavior, which dramatically increase their amounts traded.

\subsection{The role of HFTs activities on the price inefficiency at the opening and the closing}

In this subsection, we make a particular focus on the effect of activities of different categories of traders on price inefficiency over the trading session. Based on 23,439 trading days-stocks observations, we measure the price inefficiency as first-order return autocorrelations, based on the final mid-quote of 5-min intervals. Intuitively, efficient prices should be unpredictable.

Additionally, we compute variance ratios proposed by Lo and McKinlay (1988). For this purpose, we use trade-based returns and estimate the variance ratios of these returns over five-minute intervals. A variance ratio of one should imply a random walk. This allows us to test our results at a higher frequency of observation.

Conrad et al. (2015) underline that if high frequency activity merely adds noise to security prices, then we should observe variance ratios substantially smaller than one for securities in which high frequency activity is more prevalent, as high frequency quotation induced price changes are reversed. The more quickly reversals occur, the quicker variance ratios should converge to one. In contrast, if high frequency quotation is associated with persistent swings away from fundamental values, variance ratios in securities with higher levels of quotations may rise above one.

While previous studies report aggregate effect of trading or quoting activities on price efficiency, our rich dataset allows us to shed some new light on the behavior of different trading activities and their effects on price efficiency at the opening and the closing, which are two sensitive periods. Activities of different categories of traders are measured by the number of limit orders they send, by the traded dollar volume, the market-to-limit ratio, and the number of cancelled/modified orders within $0.5 \mathrm{~s}$ time span divided by number of sent limit orders. All these measures are computed over five-minute time intervals. Table 10 reports the results.

At the last-half hour of the trading session, the variance ratio at an interval of $5 \mathrm{~min}$ is on average 1.086495, that implies a random walk (Lo and McKinlay, 1988). The mean of first-order returns autocorrelation at the end of the day is -0.0001991117 . Our findings show a strong relationship between the quoting activities of mixed-HFTs (measured by the number of limit orders sent to the order 


\section{Table 10}

Relationship between market efficiency measures and the trading and quoting activities of different categories of traders. Statistics are computed over 5-minute intervals. A series of statistics are created based on 23,439 trading days-stocks observations. Nb limit orders is the number of limit orders sent to the order book by a given category of traders. Market/limit denotes number of market orders divided to number of limit orders sent over the given period. \$ Volume denotes a dollar volume $=\sum_{i=1}^{n}$ Volume $_{i}{ }^{*}$ Price $_{i}$, where Volume $\mathrm{i}$ is a volume of realized transaction $\mathrm{i}$, and Price $\mathrm{i}$ is the price of realized transaction i, C0.5LR is a number of cancelled/modified within $0.5 \mathrm{~s}$ orders divided by the number of total limit order sent to the order book over a given time period.

\begin{tabular}{|c|c|c|c|c|}
\hline \multicolumn{5}{|l|}{ First Half-Hour } \\
\hline & \multicolumn{2}{|c|}{ Variance Ratios } & \multicolumn{2}{|c|}{ Return Autocorrelations } \\
\hline & Coefficient & P-Value & Coefficient & P-Value \\
\hline Pure-HFT Nb limit orders & $-2.41 \mathrm{E}-04$ & $2.15 \mathrm{e}-14^{* * *}$ & $1.46 \mathrm{E}-06$ & $0.009221^{* *}$ \\
\hline Pure-HFT Market/Limit & -1.362 & 0.050236 & $-2.45 \mathrm{E}-02$ & 0.75934 \\
\hline Pure-HFT \$ Volume & $6.56 \mathrm{E}-06$ & $9.99 \mathrm{e}-07^{* * *}$ & $9.47 \mathrm{E}-08$ & 0.057059 \\
\hline Pure-HFT C0.5LR & -1.28 & $<2 \mathrm{e}-16^{* * *}$ & $3.09 \mathrm{E}-03$ & 0.204172 \\
\hline Mixed-HFT Nb limit orders & $-2.35 \mathrm{E}-03$ & $<2 \mathrm{e}-16^{* * *}$ & $1.06 \mathrm{E}-05$ & $7.01 \mathrm{e}-15^{* * *}$ \\
\hline Mixed -HFT Market/Limit & -3.195 & $0.000202 * * *$ & $-5.27 \mathrm{E}-02$ & $0.000466^{* * *}$ \\
\hline Mixed -HFT \$ Volume & $-2.17 \mathrm{E}-04$ & $<2 \mathrm{e}-16^{* * *}$ & $1.40 \mathrm{E}-07$ & 0.481336 \\
\hline Mixed -HFT C0.5LR & 0.9061 & $7.19 \mathrm{e}-12^{* * *}$ & $-3.10 \mathrm{E}-03$ & 0.230566 \\
\hline Non-HFT Nb limit orders & $-1.48 \mathrm{E}-03$ & $3.35 \mathrm{e}-13^{* * *}$ & $-5.61 \mathrm{E}-07$ & 0.821386 \\
\hline Non -HFT Market/Limit & -1.513 & $<2 \mathrm{e}-16^{* * *}$ & $4.52 \mathrm{E}-04$ & 0.883861 \\
\hline Non -HFT \$ Volume & $6.39 \mathrm{E}-06$ & 0.133885 & $-7.97 \mathrm{E}-09$ & 0.868796 \\
\hline Non -HFT C0.5LR & 0.7709 & $<2 \mathrm{e}-16^{* * *}$ & $-1.85 \mathrm{E}-03$ & 0.13069 \\
\hline \multicolumn{5}{|l|}{ Last Half-Hour } \\
\hline & \multicolumn{2}{|c|}{ Variance Ratios } & \multicolumn{2}{|c|}{ Return Autocorrelations } \\
\hline & Coefficient & P-Value & Coefficient & P-Value \\
\hline Pure-HFT Nb limit orders & $-3.64 \mathrm{E}-05$ & 0.081888 & $3.13 \mathrm{E}-08$ & 0.837 \\
\hline Pure-HFT Market/Limit & -0.3985 & 0.856663 & -1.74 & 0.278 \\
\hline Pure-HFT \$ Volume & $2.04 \mathrm{E}-05$ & $<2 \mathrm{e}-16^{* * *}$ & $8.58 \mathrm{E}-09$ & 0.581 \\
\hline Pure-HFT C0.5LR & -0.4875 & $0.004515^{* *}$ & $3.53 \mathrm{E}-04$ & 0.777 \\
\hline Mixed -HFT Nb limit orders & $-4.40 \mathrm{E}-04$ & $9.79 \mathrm{e}-11 * * *$ & $-1.93 \mathrm{E}-08$ & 0.969 \\
\hline Mixed -HFT Market/Limit & -2.813 & $5.01 \mathrm{e}-05^{* * *}$ & $2.53 \mathrm{E}-02$ & 0.616 \\
\hline Mixed -HFT \$ Volume & $-8.02 \mathrm{E}-05$ & $<2 \mathrm{e}-16^{* * *}$ & $5.75 \mathrm{E}-08$ & 0.395 \\
\hline Mixed -HFT C0.5LR & 0.1381 & 0.4641 & $-4.38 \mathrm{E}-04$ & 0.749 \\
\hline Non -HFT Nb limit orders & $-6.27 \mathrm{E}-04$ & $0.000124 * * *$ & $4.63 \mathrm{E}-07$ & 0.696 \\
\hline Non -HFT Market/Limit & -1.159 & $2.22 \mathrm{e}-07 * * *$ & $-6.79 \mathrm{E}-04$ & 0.676 \\
\hline Non -HFT \$ Volume & $-2.20 \mathrm{E}-06$ & 0.578533 & $-2.20 \mathrm{E}-08$ & 0.444 \\
\hline Non -HFT C0.5LR & 0.4119 & $8.98 \mathrm{e}-05^{* * *}$ & $3.18 \mathrm{E}-04$ & 0.677 \\
\hline
\end{tabular}

book) and the market inefficiency measured by the variance ratios of returns at the end of the day (with a coefficient of regression equals to $-4.40 \mathrm{E}-04$ with a $\mathrm{p}$ - value equals to $9.79 \mathrm{e}-11$ ). For the non-HFTs, the coefficient of regression is equal to $6.27 \mathrm{E}-04$ with a $\mathrm{p}$ - value equals to 0.000124). At the same time, we find a significant relationship between the cancelled/modified orders within $0.5 \mathrm{~s}$ to sent orders ratio of pure-HFTs and the variance ratios (with a coefficient of regression that is equal to 0.4875 and a $\mathrm{p}-\mathrm{value}$ equals to 0.004515$)$.

We report a deterioration of market efficiency at the first half-hour of trading. The autocorrelation of returns at that period is close to zero, while the variance ratios are significantly higher than one. Our results show a particular a strong influence of Mixed-HFTs quoting activities on market efficiency measured by both the variance ratios and the autocorrelation of returns. Their activities have the greatest impact on deviates from fundamentals resulting by variance ratios significantly different from one. Our regression analysis shows also the existence of a strong relationship between the trading activities measured by dollar volume of this category and the autocorrelation of returns (with a coefficient of regression that is equal to $-5.27 \mathrm{e}-02$ and a $\mathrm{p}-$ value equal to 0.000466 ).

Overall, our results show that the pure-HFTs and the mixed-HFTs are the main drivers of the price efficiency at the beginning and at the end of the day when we observe the data at a frequency of 5-minute intervals. These results converge with those for the normalized volatility ratios based on the half-hour intervals. In modern markets, the High-Frequency traders (HFTs) play an important role in providing liquidity. These results are confirmed by Hasbrouck and Saar (2013) and Conrad et al. (2015).

However, the volume of data generated by HFT and the speed of the operations can make it especially challenging market supervision by regulating authorities. In the world, several cases of "price manipulation" with different strategies affecting the price efficiency have been detected. ${ }^{14}$

The Autorité des Marchés Financiers' (AMF) Enforcement Committee handed down a penalty of $€ 5$ million to Virtu Financial Europe for its role in market manipulation as well as circumventing Euronext's market rules in 2009 - at the same time, the regulator

\footnotetext{
${ }^{14}$ See Kraay Trading in 2011 with cancelled orders, Athena Capital Research in 2014 with the strategy of marking the close, Michael Coscia in 2013 with spoofing and Virtu in 2009 with the market manipulation through its orders.
} 
also fined Euronext Paris for the same amount for effectively failing to meet its obligation to operate with neutrality and impartiality, according to a regulatory statement. ${ }^{15}$ The market integrity is particularly important in this context.

In the EU, the revision of MiFID through MiFID II adds safeguards to orderly functioning of markets. Firstly, MiFID II (implemented since 2018) provides a test ${ }^{16}$ to define what is High-Frequency Trading and to determine who is concerned with the new rules concerning Algorithmic trading. If the firm is deemed as involved in "Algo" / HFT trading, by definition of MiFID II, then the firm is required to become authorized as an investment firm and to comply with compulsory market-making rules. The rules should ensure that the "Algorithmic" system has appropriate controls which prohibit sending erroneous orders during operations that does not contribute to disorderly market and not violate the trading venues rules.

Also, the High-Frequency Traders will be required to store all time-sequenced records in detail for a minimum of 5 years. These stored records, which will be made available to the regulatory body, must encompass the following details: the person in charge of each algorithm, the description of each decision made or trade by the algorithm and the Compliance and Risk Controls.

The records must be made available to the Member State competent authority on request. Moreover, the trading venues must provide facilities for their members to test algorithms, identify orders generated by algorithms and ensure that algorithmic trading cannot create or contribute to disorderly trading. In fact, the venues are required to manage such harmful conditions by slowing down order flow, limiting the ratio of unexecuted orders to transactions and regulating minimum tick sizes and circuit breakers. These questions are extremely sensitive.

Jones (2013) underline that the regulators should appropriately rely on competition to minimize abuses. If there is some sort of market failure, however, then robust competition may not always be the solution, and regulation may be in order. The current regulatory initiatives include Consolidated order-level audit trails, Order cancellation or excess message fees, Minimum order exposure times and the Securities transaction taxes (such as in France and in Italy).

These initiatives should be studied carefully to avoid a reduction in market quality, including volatility, price discovery and liquidity. Some new policies, such as short-term price limits and circuit breakers, seem well-crafted to address specific problems that arose during the flash crash. Other regulatory tweaks such as kill switches may be in order, but those formulating policy should be especially careful not to reverse the market quality improvements.

To control for the impacts of market disruptions on the High-Frequency market activities, such as the French Securities Transaction Tax (STT) that was implemented in August 2012 in France, we have developed an additional section on the effects of Financial Transactions Tax (FTT) implemented in France in 2012 on market quality and traders' activities. On August 1st 2012, France introduced a tax on financial transactions that comprises three different taxes: (i) a tax on the acquisition of equity securities; (ii) a tax on HFT; and (iii) a tax on naked sovereign Credit Default Swaps (CDS). The first tax (i) concerned 108 large capitalizations ( $>=1$ billion euros).

The tax on HFT is a $0.01 \%$ tax on the amount of cancelled or modified orders within a half-second time span, on a given trading day, which exceeds a threshold of $80 \%$ of total submitted orders.

Our paper is closely related to existing studies using the introduction of the FTT in France in 2012 to examine the effect of the FTT on market quality. Our study differs from these studies in one important way. Current paper shows on the one hand the effects of this tax on market quality and on the other hand on trading activities, which could potentially explain the changes in market quality measures.

In our regression for the year 2012-2013, the impact of the French Securities Transaction Tax (STT) is not significant. To control for other determinants of volatility, we included the average price of the stock, the monthly volatility and the monthly trading volume as control variables in our regression for the year 2012-2013. These variables are not significant in 2012-2013. This result of no significant effect on volatility is consistent with Capelle-Blancard and Havrylchyk (2016) and Veryzhenko et al. (2017).

We add these two references in our paper to explain this point. Veryzhenko et al. (2017) conclude that HFTs help the faster dissemination of this information within the market, and improve price efficiency. These results are in line with the empirical study by Brogaard et al. (2014), which shows that, through marketable orders, HFTs increase price efficiency by trading in the direction of permanent price changes. Next, we realize a deep analysis on the effects of the French Financial Transaction Tax on High-Frequency market activities. We focus on several metrics to describe the trading activities of different categories of market participants. We propose the following ratios:

- Cancelled to Sent Ratio (CSR) = Number of cancelled orders/Number of sent orders. The numerator includes all cancelled orders The denominator includes all types of order markets and limits submitted by a given category of traders.

- Dollar Cancellation Ratio (DCR) = Total dollar volume cancelled/Sum of dollar volume submitted. The numerator of this ratio presents the volume times price of all cancelled orders by a certain category of traders. The denominator presents the volume times price of all submitted orders to the order book.

- Cancelled to Limit Orders Ratio (CLR) = Number of cancelled orders/Number of sent limit orders

- Market-To-Limit Orders Ratio (MTL) = Number of sent market order/Number of sent limit orders

\footnotetext{
$\overline{15}$ For more information, see https://www.amf-france.org/fr/actualites-publications/communiques/la-commission-des-sanctions-de-lautorite-desmarches-financiers-sanctionne-virtu-financial-europe-et.

16 Article 4(1)(40) of MiFID 2 has enacted High-Frequency Trader as a subset of the Algorithmic Trading definition and it concerns traders with at least 2 messages per second with respect to any single financial instrument traded on a trading venue or at least 4 messages per second with respect to all financial instruments traded on a trading venue.
} 
- Cancelled within $0.5 \mathrm{~s}$ to Sent Limit Orders Ratio (C5LR) = Number of cancelled within $0.5 \mathrm{~s}$ orders/Number of sent limit orders.

We use a simple Difference-in-Differences approach for identifying the effect of the French Financial Transaction Tax (FTT) on trading activities. We are particularly interested in the relationship between cancel-order tax and High-Frequency traders' activity. For this purpose, we compare our sample of French stocks to the control group of untaxed stocks. Our sample consists of 87 French stocks traded on Euronext with a market capitalization above 1 billion euros, thus subject to the FTT and 27 stocks of the French companies traded on Euronext Paris with a market capitalization bellow 1 billion euros for our control group. We use a six-month sample period (3 months before- and after the FTT implementation) with a trade-based frequency of observations.

Table 11 reports the impacts of the three-fold tax introduced in France on the trading activities of different categories of market participants. Our findings show relatively small effect of this tax on traders' activities. We report a significant increase in Dollar Cancellation Ratio for the pure-HFTs and the non-HFTs. It can be explained by the fact that tax on acquisition is applied only when positions are held overnight, so the pure-HFTs and the non-HFTs tend to revise carefully their positions. We also find that the FTT has increased the aggressiveness of traders' quotation, represented through the Market-To-Limit Orders Ratio. The mixed-HFTs reduced their use of limit orders in favor of market orders. According to Brogaard et al. (2014) such marketable orders of HFTs increase price efficiency. Our findings also show an insignificant effect of the FTT on the cancellation within half a second time span to the total number of sent limit orders for the HFTs and the mixed-HFTs. We can conclude that the tax on HFT had weak effect on quoting activities of these categories.

This phenomenon can be explained by the fact that this tax applies only to French actors, who are minimally affected because of an exemption applied to market-making activities, and because of the very high threshold. Based on the first results, the government estimates that the tax on HFT generated no revenue in 2012.

\section{Conclusion}

With the implementation of the MiFID, the equity market has seen a multiplication of trading venues and the fragmentation of order flow. The purpose of this paper is to study the evolution of the intra-day volatility patterns after the implementation of the MiFID for the trading activity on the NYSE Euronext Paris and for the quoting activity between this index and the MTFs (BATS and Chi-X). Based on the normalized volatility ratios, we analyze the evolution of intraday price efficiency in 2006 and 2012-2013 for the French blue-chip stocks.

Moreover, we study how market fragmentation harms short-term volatility and price efficiency at the opening of the NYSE Euronext Paris for transaction prices. First, we report a significantly increased spatial fragmentation after the implementation of MiFID, based on the FFI for each stock per month. Additionally, we report an increased temporal fragmentation defined as the average monthly number of transactions since the implementation of the MiFID in Europe. Consequently, our findings show that liquidity for the CAC40 stocks does not belong to the NYSE Euronext Paris. On average, we need at least two trading venues to rebuild liquidity on the Lit market. At this level, the BATS and Chi-X Europe located in London, have been the two main MTFs trading the CAC40's stocks since the implementation of the MiFID.

Second, we report a U-shaped pattern of the intra-day volatility for the trading on the NYSE Euronext Paris and for the quoting activity on all studied trading venues after the implementation of the MiFID in 2007. The accentuated periods of volatility are more pronounced at market opening.

These results confirm some price inefficiencies at market opening compared to the average midday values. For the quoting activity, the accentuated short-term volatility at market opening is more pronounced for the NYSE Euronext Paris than for the BATS and Chi-X Europe. Our results confirm that the openings are periods of high order imbalances that need time to be aligned with the consensus values, given that information may be released since the previous closing period.

The closing period is much more efficient after the implementation of the MiFID. It shows the positive effect of the closing call on

Table 11

Effects of the three-fold tax implemented in France on August 1, 2012 on activity measures of different categories of traders. Difference-in-differences analysis. Values in parentheses correspond to $\mathrm{p}-$ value to assess the statistical significance of results. ***, $* * *$, and '. ' denote statistical significance at the $0 \%, 0.1 \%, 1 \%$, and $5 \%$ level, respectively. This table reports different proxies of trading activities: $\mathbf{D C R}=$ Total dollar volume cancelled/Sum of dollar volume submitted, CLR $=$ Number of cancelled orders/ Number of sent orders, MTL $=$ Number of sent market orders/Number of sent limit orders, C5LR $=$ Number of cancelled within $0.5 \mathrm{~s}$ orders/Number of sent limit orders.

\begin{tabular}{|c|c|c|c|}
\hline & Pure-HFT & Mixed-HFT & Non-HFT \\
\hline \multirow[t]{2}{*}{ DCR } & 0.11856 & -0.034085 & 0.080434 \\
\hline & $\left(5.23 e-08^{* * *}\right)$ & $(0.0349 *)$ & $\left(7.99 e-07^{* * *}\right)$ \\
\hline \multirow[t]{2}{*}{ CLR } & -0.022683 & 0.003393 & 0.063108 \\
\hline & 0.224 & 0.758 & $\left(0.000103^{* * * *}\right)$ \\
\hline \multirow[t]{2}{*}{ MTL } & $-3.71 \mathrm{E}-06$ & 1.30E-03 & 0.00831 \\
\hline & 0.57222 & $\left(<2 e-16^{* * *}\right)$ & 0.163 \\
\hline \multirow[t]{2}{*}{ C5LR } & -0.017032 & -0.012622 & -0.0025625 \\
\hline & 0.128 & 0.171 & $\left(3.68 e-06^{* * *}\right)$ \\
\hline
\end{tabular}


the market quality on all market venues. In line with Pagano et al. (2013) and Pagano and Schwartz (2003), we find that the closing call auction encourages more efficient price behavior at market closing by controlling price volatility in the continuous market. Additionally, our analysis of the open-to-close normalized volatility ratios indicates the existence of intra-day trends on average, with price dislocations that may be attributable to one of four market factors (spreads, market impact, dynamic price discovery and momentum trading).

These price dislocations have not been repaired by the price reversals that have occurred by the end of the trading day because the price reversal occurs on several days and intraday trends predominate over a longer period. Our results confirm those of Wood et al. (1985), Chan et al. (1995), Ozenbas et al. (2002) and Ozenbas et al. (2011). We also report as significant relationship between the number of trades, short-term volatility and price inefficiencies at market opening. After the implementation of MiFID, more trades are needed before a relatively stable price is found on heavy volume days. It can be explained by the complexity of price discovery. Thus, the number of trades in the opening half-hour can be considered as a good proxy for increased price discovery activity.

Additionally, our results bring some evidence that spatial fragmentation does not cause price inefficiencies at market opening after the implementation of the MiFID for fragmented stocks. Spatial fragmentation has enhanced the competitive nature of EU equity markets without deteriorating transactional or informational efficiency. However, temporal fragmentation, measured by the monthly average number of transactions, is a more significant explanation of accentuated short-term volatility and price inefficiencies at market opening. The price inefficiency at market opening is lower for actively traded stocks. Moreover, an active participation of HighFrequency traders at market opening reduces the amplified short-term volatility and improves market efficiency. Nevertheless, it is important to ensure market integrity and market quality for the future in our High-Frequency world.

\section{Declaration of Competing Interest}

The authors declare that they have no known competing financial interests or personal relationships that could have appeared to influence the work reported in this paper.

\section{Acknowledgements}

We address special thanks to Eurofidai and the director Patrice Fontaine for providing the AMF (Autorité des marchés financiers) EUROFIDAI/BEDOFIH European High Frequency database. More information on the BEDOFIH European High Frequency financial database can be found at the following link: https://www.eurofidai.org/en/bedofih-database. Moreover, we address special thanks to INSEAD OEE Data Services (IODS) and the director Didier Davydoff for providing the data for the main sample on BATS and Chi-X. We are particularly grateful to the Laboratory PRISM-Sorbonne and the Laboratory of Excellence on Financial Regulation (Labex ReFi). We gratefully acknowledge the support of ANR, The French National Research Agency.

Further, we wish to thank Selma Boussetta, Carole Gresse, Thierry Foucault, Joel Hasbrouck, Maureen O'Hara, Jean-Paul Laurent, Christine Parlour, Ioanid Rosu, Patrice Sentis and William Ziemba for their useful comments and suggestions, as well as participants at the 2015 JIRF.

(Universite de Bourgogne, Dijon), the 2016 Research Day in Management (Solvay Business School (ULB), Brussels), the 2016 Conference on Quantitative Methods for Financial Regulation (Stony Brook University, New York) and the 2018 International Conference on Digital Innovation and Financing (INSEEC-U, Lyon) and the participants at the finance seminars of the University Paris I Pantheon-Sorbonne. Lastly, we would like to deeply acknowledge Gideon Saar and two anonymous referees for their challenging reviews, which substantially improved this work. The analysis, the interpretations and the conclusions of this study are the own responsibility of authors and they are not meant to represent the stances of the AMF.

\section{Funding}

This work was achieved through the Laboratory of Excellence on Financial Regulation (Labex ReFi) under the reference ANR10LABEX-0095. It benefitted from a French government support managed by the National Research Agency (ANR) within the project Investissements d'Avenir Paris Nouveaux Mondes (investments for the future Paris-New Worlds) under the reference ANR-11IDEX-0006-02.

\section{References}

Aitken, M., Cumming, D., Zhan, F., 2015. High-Frequency trading and end-of-day price dislocation. J. Bank. Finance 59, 330-349.

Aitken, M., Chen, H., Foley, S., 2017. The impact of fragmentation, exchange fees and liquidity provision on market quality. J. Empirical Finance 41, 140-160. AMF (2017). https://www.amf-france.org/en/news-publications/publications/reports-research-and-analysis/study-behaviour-high-frequency-traders-euronextparis.

Bennett, P., Wei, L.i., 2006. Market structure, fragmentation, and market quality. J. Financial Markets 9 (1), 49-78.

Baruch, S., Glosten, L., 2013. Flickering quotes. Columbia University.

Biais, B., Foucault, T., 2014. HFT and market quality. Bank. Markets Invest. 128, 5-19.

Biais, B., Hillion, P., Spatt, C., 1999. Price discovery and learning during the preopening period in the Paris bourse. J. Political Econ. 107 (6), $1218-1248$.

Boussetta, S., Lescourret, L., Moinas, S., 2017. The role of preopening mechanisms in fragmented markets. Northern Finance Association (NFA) 2018 Annual Conference.

Brogaard, J., Riordan, R., 2019. Price discovery without trading: evidence from limit orders. J. Finance 74, 1621-1658.

Brogaard, J., Hendershott, T., Riordan, R., 2014. High-frequency trading and price discovery. Rev. Financial Stud. 27 (8), $2267-2306$. 
Brogaard, Jonathan, et al., 2010. High frequency trading and its impact on market quality. Northwestern University Kellogg School of Management Working Paper, 66.

Buckle, M., Chen, J., Guo, Q., Li, X., 2018. The impact of multilateral trading facilities on price discovery. Financial Markets, Inst. Instrum. 27 (4), 145-165.

Capelle-Blancard, G., Havrylchyk, O., 2016. The impact of the french securities transaction tax on market liquidity and volatility. Int. Rev. Financial Anal. 47, 166-178.

Carrion, A., 2013. Very fast money: High frequency trading on the NASDAQ. J. Financial Markets 16 (4), $680-711$.

Chaboud, A.P., Chiquoine, B., Hjalmarsson, E., Vega, C., 2014. Rise of the machines: Algorithmic trading in the foreign exchange market. The. Journal of Finance 69 (5), 2045-2084.

Chan, Kalok C., Christie, William G., Schultz, Paul H., 1995. Market structure and the intraday pattern of bid ask spreads for NASDAQ securities. Journal of Business 35-60.

Clapham, B., Zimmermann, K., 2016. Price discovery and convergence in fragmented securities markets. Int. J. Managerial Finance 12 (4), $381-407$.

Colliard, J.-E., Foucault, T., 2012. Trading fees and efficiency in limit order markets. Rev. Financial Stud. 25 (11), $3389-3421$.

Conrad, J., Wahal, S., Xiang, J., 2015. High-frequency quoting, trading, and the efficiency of prices. J. Financ. Econ. 116 (2), $271-291$.

Foucault, T., Menkveld, A.J., 2008. Competition for order flow and smart order routing systems. J. Finance 63 (1), $119-158$.

Gajewski, J.-F., Gresse, C., 2007. Centralised order books versus hybrid order books: A paired comparison of trading costs on NSC (Euronext Paris) and SETS (London Stock Exchange). J. Bank. Finance 31 (9), 2906-2924.

Gomber, P., Sagade, S., Theissen, E., Weber, M., Westheide, C., 2017. Competition between equity markets: a review of the consolidation versus fragmentation debate. J. Econ. Surveys 31 (3), 792-814.

Gresse, C., 2017. Effects of lit and dark market fragmentation on liquidity. J. Financial Markets 35, 1-20.

Hagströmer, B., Nordén, L., 2013. The diversity of high frequency traders. J. Financial Markets 16 (4), 741-770.

Handa, P., Schwartz, R., 1996. Limit order trading. J. Finance 51 (5), 1835-1861.

Harris, L.E., 1993. Consolidation, fragmentation, segmentation, and regulation. J. f Finance 48, 1092-1093.

Hasbrouck, J., Schwartz, R.A., 1988. Liquidity and execution costs in equity markets. J. Portfolio Manage. 14 (3), $10-16$.

Hasbrouck, J., 1995. One security, many markets: Determining the contributions to price discovery. J. Finance 50 (4), 1175-1199.

Hasbrouck, J., Saar, G., 2013. Low latency trading. J. Financial Markets 16 (4), 646-679.

Hendershott, T., Jones, C.M., Menkveld, A.J., 2011. Does algorithmic trading improve liquidity? J. Finance 66 (1), 1-33.

Ibikunle, G., Mare, D., Sun, Y., 2020. The paradoxical effects of market fragmentation on adverse selection risk and market efficiency. Eur. J. Finance 84, 1-23.

Jones, Charles M., 2013. What Do We Know About High-Frequency Trading? Columbia Business School Research Paper No. 13-11.

Lo, A., McKinlay, A., 1988. Stock market prices do not follow random walks: evidence from a simple specification test. Rev. Financial Stud. 1 (1), $41-66$.

Madhavan, A., 1995. Consolidation, fragmentation, and the disclosure of trading information. Rev. Financial Stud. 8 (3), $579-603$.

Ozenbas, D., Schwartz, R., Wood, R., 2002. Volatility in US and European equity markets: an assessment of market quality. Int. Finance 5 (3), $437-461$.

O'Hara, M., Ye, M., 2011. Is market fragmentation harming market quality? J. Financ. Econ. 100 (3), $459-474$.

Ozenbas, D., Pagano, M., Schwartz, R., 2010. Accentuated intraday stock price volatility: What is the cause? J. Portfolio Manage. 36 (3), $45-55$.

Ozenbas, D., Pagano, M.S., Schwartz, R.A., 2011. Accentuated intraday stock price volatility. In: Volatility. Springer, Boston, MA, pp. 111-126.

Pagano, M., Schwartz, R., 2003. A closing call' impact on market quality at Euronext Paris. J. Financ. Econ. 68 (3), $439-484$.

Pagano, M., Peng, L., Schwartz, R., 2013. A call auction's impact on price formation and order routing: evidence from the Nasdaq stock market. J. Financial Markets $16(2), 331-361$.

Riordan, R., Storkenmaier, A., 2012. Latency, liquidity and price discovery. J. Financial Markets 15 (4), $416-437$.

Saliba, P., 2020. The information content of High-Frequency traders aggressive orders: recent evidence. Quant. Finance 20 (11), $1779-1794$.

Schwartz, R., 2010. Dark pools, fragmented markets, and the quality of price discovery. J. Trading 5 (2), 17-22.

Veryzhenko, I., Harb, E., Louhichi, W., Oriol, N., 2017. The impact of the French financial transaction tax on HFT activities and market quality. Econ. Model. 67, 307-315.

Wood, Robert A., McInish, Thomas H., Keith Ord, J., 1985. An investigation of transactions data for NYSE stocks. The Journal of Finance 40 (3), $723-739$. 